\title{
Effects of a Group of High-Rise Structures on Ground Motions under Seismic Excitation
}

\author{
Qing-jun Chen and Wen-ting Li \\ State Key Laboratory of Disaster Reduction in Civil Engineering, Tongji University, Shanghai 200092, China \\ Correspondence should be addressed to Wen-ting Li; 1410002@tongji.edu.cn
}

Received 21 April 2015; Revised 14 July 2015; Accepted 30 July 2015

Academic Editor: Matteo Aureli

Copyright (C) 2015 Q.-j. Chen and W.-t. Li. This is an open access article distributed under the Creative Commons Attribution License, which permits unrestricted use, distribution, and reproduction in any medium, provided the original work is properly cited.

\begin{abstract}
A three-dimensional simulation was created to determine the seismic performance of coupled systems with a group of up to 100 pile-high-rise structures resting on soil layers using system modal, harmonic, and time domain analysis. The results demonstrated that the existence of a structural group mitigates the structural responses with respect to the single-structure-soil interaction (SSI) and results in significantly nonuniform ground seismic motions. Due to the influence of a structural group, adjacent structures can exhibit fully alternating mechanical behavior, and buildings in the urban fringe are subjected to stronger shaking than downtown buildings. The overall trend of the influence of structural groups is that ground motions are lessened inside an urban area, and ground motions at the locations between structures differ from those at the locations of the structures. Moreover, the effective distance of a structural group on ground motions is associated with the urban width. Less distance between structures enhances the interaction effect. In addition, the soil properties can greatly influence the system's seismic responses and can even completely change the effect trends. The results in our paper are consistent with the phenomena observed in the Mexico City earthquake and the 1976 earthquake in Friuli, Italy.
\end{abstract}

\section{Introduction}

Interest in seismic hazards and the performance of structures during earthquakes has steadily increased in recent years. The 1985 earthquake in Michoacán, Mexico, renewed our appreciation of earthquake engineering by demonstrating that urban areas can suffer from particularly long and strong ground motions. This earthquake exhibited specific characteristics that have been encountered at various other locations [1-3]. Another example is the devastating 2009 L'Aquila earthquake in central Italy. According to some researchers [4-6], the large amplitudes of the signals and their particularly long durations may have been due to the interaction with the building environment itself. The increasing complexity of urban structures impels research on the structure-soil-structure interaction, which is substantial and leads to considerable conceptual changes, with particular relevance for microzoning studies, urban planning, and insurance policies.

The structure-soil-structure interaction (SSSI), also called site-city interaction (SCI), focuses on the seismic performance of an urban-like environment. In the soil-structure interaction (SSI), part of the vibrational energy of the flexibly mounted structure is dissipated by the radiation of stress waves in the supporting medium and by hysteretic action in the medium itself. The waves, which are composed of the relative motions of the inertial soil, can take energy away from the basement and act as dampers for the structure. The history of SSI, which has been well summarized by Kausel [7] and Çelebi et al. [8], is elided here. Many researchers have studied this subject [9-16]. Bielak [17] has presented an approximate method of modal analysis of the earthquake response of linear building-foundation systems. The effect of hysteretic soil damping on the system response has been illustrated by several examples. Jarernprasert et al. [18] have analyzed the effects of SSI on the response of yielding singlestory structures embedded in an elastic half-space to a set of accelerograms. They found that, for nonlinear hysteretic structures, SSI may lead to larger ductility demands and larger total displacements than if the soil were rigid; the period elongation ratio controls the response of SSI systems with nonlinear structures; and SSI leads to a smaller reduction factor for the seismic coefficient due to nonlinear behavior. 


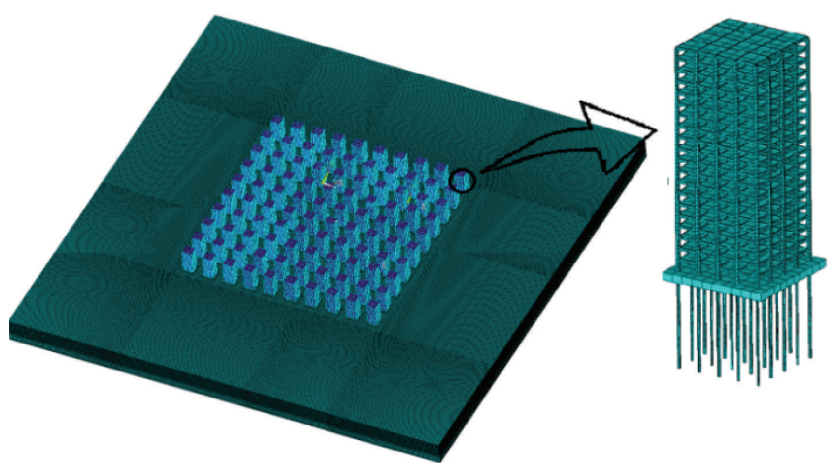

FIGURE 1: 3D finite element model.

They have developed a procedure to estimate the SSI seismic coefficient to maintain target ductility and provided an approach that allows the importance of SSI drift or peak structural displacement to be assessed.

When accounting for SSSI, the SSI problem evolves into a cross-interaction problem among multiple structures. Whitman [19] first introduced the through-the-soil coupling of foundations in 1969, which was an important problem that required further study. Soon after, Luco and Contesse [20], followed by Wong and Trifunac [21], addressed the twodimensional antiplane problem of the interaction between infinite walls under incident $\mathrm{SH}$ waves, which used a solution for the interaction among semicircular, semi-infinite crosssectional foundations. Later, two different finite elementboundary element-coupling models were used by Wang and Schmid [22] and Lehmann and Antes [23] to investigate the dynamic interaction between the three-dimensional structures founded on square embedded foundations; several works have addressed this topic [24-31]. Padrón et al. [32] numerically studied the dynamic through-soil interaction between nearby pile-supported structures in viscoelastic halfspace under incident $S$ and Rayleigh waves. Naserkhaki et al. [33] examined both the interaction between adjacent buildings due to pounding and the interaction between buildings through the soil, as these factors affect the buildings' seismic responses. Aldaikh et al. [34] explored the adverse and beneficial effects of SSSI under seismic excitation on a group of three buildings. In addition, much experimental evidence has shown that vibrations transmitted from a building to the ground can propagate over large distances. The Nuclear Power Engineering Corporation (NUPEC) has been planning and implementing field and laboratory tests under the project "Model Test on Dynamic Cross Interaction Effect of Adjacent Structures." Detailed data are available in papers by Kitada [35-37]. Ha and Kim [38] performed a series of dynamic centrifuge tests with various soil conditions that ranged from loose sand to weathered rock (WR) with different seismic intensities of bedrock motion.

These previous works were mostly based on simple models with limited analytical methods and simulation tools, which were clearly inadequate for obtaining an acceptable solution to such problems. A clear understanding of the basic effects of SCI has yet to be obtained due to either the complexity of the site-city models (3D effects, irregular city) or the restrictive assumptions (homogenization of the site-city medium) [39]. As the heights of superstructures continue to increase, a study on the dynamic cross-interactions in an urban-like environment consisting of structural groups is necessary.

In this paper, full three-dimensional (3D) FEM models with pile-high-rise structures resting on soil layers (see Figure 1) under seismic wave excitation are studied. The goal is to understand how the presence of a structural group affects the structural seismic performance and how the presence of a structural group affects the seismic response of soil. Based on the characteristics of structures, the influence of SSSI is evaluated from the structural base horizontal acceleration amplitude and absorbed energy; based on the characteristics of ground motions, the SSSI influence is investigated from the instantaneous acceleration field, peak ground acceleration (PGA) distribution, ground energy density, and the effective distance of a structural group.

\section{Problem Definition}

The SSSI system under investigation is composed of one or more common pile-high-rise square frame structures founded on fixed-head pile groups embedded into horizontal soil layers. To concentrate on the regularities of the coupling system, all structures in the urban environment are copies of the same structure with equal spacing between all structures within the same problem. The finite element model is depicted in Figure 1. The total height of the structure is $60 \mathrm{~m}$; the width (square) of the structure is $24 \mathrm{~m}$. The number of stories is 20 , with a pile length of $24 \mathrm{~m}$ and a pile sectional diameter of $0.35 \mathrm{~m}$. The dynamic behavior of several problems (whose different relative arrangements of structures are shown in Figure 2, termed as URBANN_M, where $N$ is the number of structures along the $X$-axis and $M$ is the number of structures along the $Y$-axis) under vertically incident shaking (producing motion along the $X$ axis, termed " $S X$ " and along the $Y$-axis, termed " $S Y$ ") from a rigid bedrock surface (depth $=60 \mathrm{~m}$ ) is analyzed. Note that, in all arrangements, the distance between adjacent structures is measured parallel to the $X$ - and $Y$-axes. The response of each structure in a structural group is compared with that of 


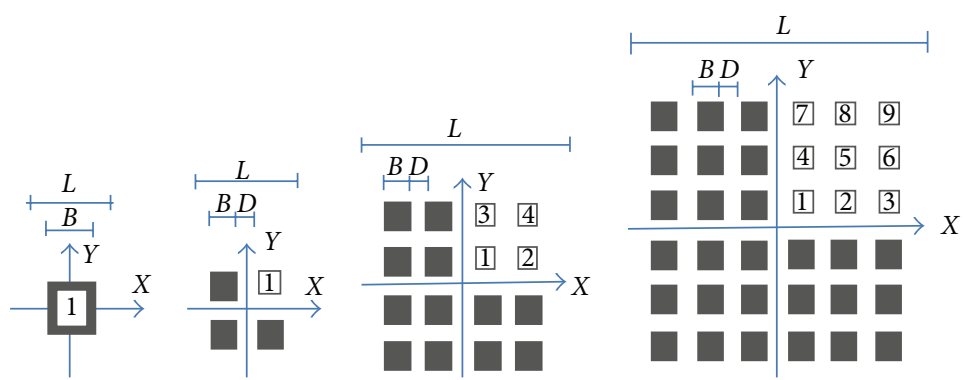

(a)

URBAN1-1

(SSI) (b)

URBAN2-2 (d) URBAN6-6

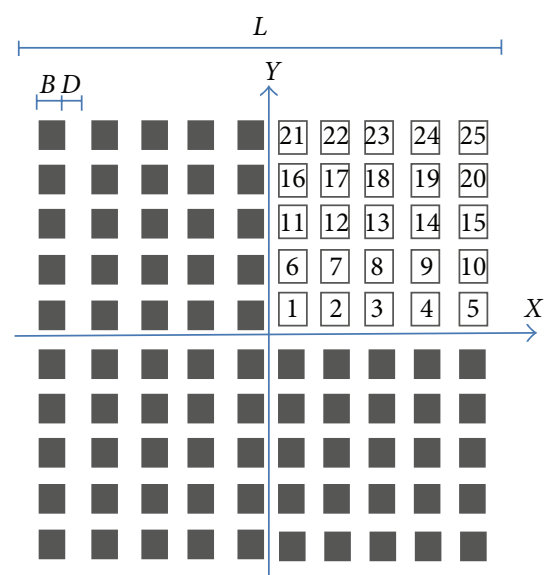

(e) URBAN10-10

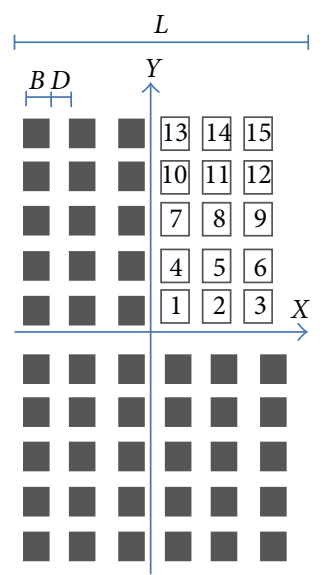

(f) URBAN6-10

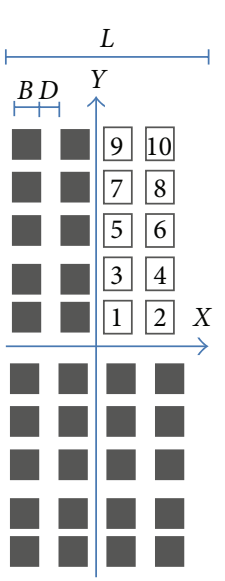

(g) URBAN4-10

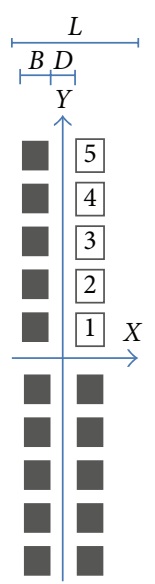

(h) URBAN2-

10

FIGURE 2: Arrangement of the structural groups.

the single-structure-soil system (SSI) to determine whether SSSI effects among several structures are important.

The underlying soil consists of 10 layers (see Table 1 for the original soil profile properties). In the standard case, the equivalent shear wave velocity of soil is $361 \mathrm{~m} / \mathrm{s}$, where the shear wave velocity terms are in vector $v_{s}$. The nonlinear phase of the soil in a strong shock is considered using the equivalent linearization method.

It should be noted that all the model analyses (only except the modal analysis of the structure with a fixed base, which is conducted for a single structure), harmonic analyses, and time domain analyses in this paper are for the whole SSSI or SSI system, not for a single structure.

\section{Finite Element Model}

The commercial finite element software ANSYS was used for the system modal analysis and system harmonic analysis; the commercial finite element software LS-DYNA was used for the system time domain analysis. The length of the soil element $l_{e}$ is limited to less than one-fifth of the wavelength $\lambda_{s}: l_{e}<(1 / 5) \lambda_{s}=\left(1 / 5 f_{N F}^{\prime}\right) v_{s}$, where $f_{N F}^{\prime}$ is the cutoff frequency (cutoff frequency is $25 \mathrm{~Hz}$ herein) and $v_{s}$ is the wave velocity. In the horizontal direction, the wave velocity
TABLE 1: Original soil profile properties.

\begin{tabular}{lcclc}
\hline Number & Depth $/ \mathrm{m}$ & $v_{s} /(\mathrm{m} / \mathrm{s})$ & Type & Density $/\left(\mathrm{kg} / \mathrm{m}^{3}\right)$ \\
\hline 1 & 2 & 150 & Clay & 1923 \\
2 & 8 & 200 & Clay & 1923 \\
3 & 14 & 250 & Clay & 1923 \\
4 & 22 & 300 & Clay & 2004 \\
5 & 31 & 350 & Sand & 2004 \\
6 & 39 & 400 & Sand & 2004 \\
7 & 47 & 500 & Sand & 2084 \\
8 & 52 & 600 & Sand & 2084 \\
9 & 56 & 800 & Rock & 2244 \\
10 & 60 & 1000 & Rock & 2244 \\
11 & Bedrock & 2000 & Rock & 2244 \\
\hline
\end{tabular}

is controlled by the traveling wave; in the depth dimension, the wave velocity is controlled by the soil shear wave velocity. The artificial boundary is six times that of the soil depth away from the edge of the urban area. This distance is considered adequate to prevent wave reflections generated at the model boundaries from reentering the model and contaminating the results. 


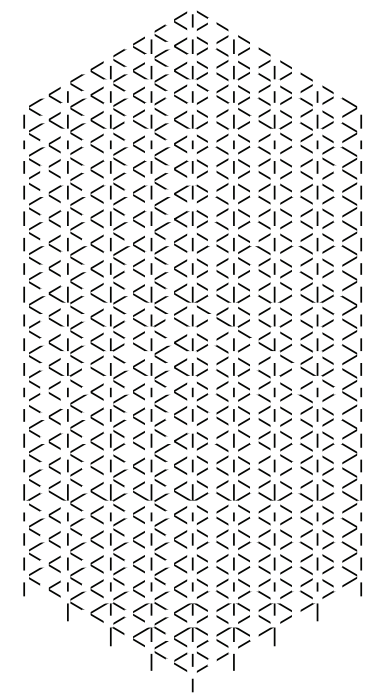

FIGURE 3: FE model of SASSI.

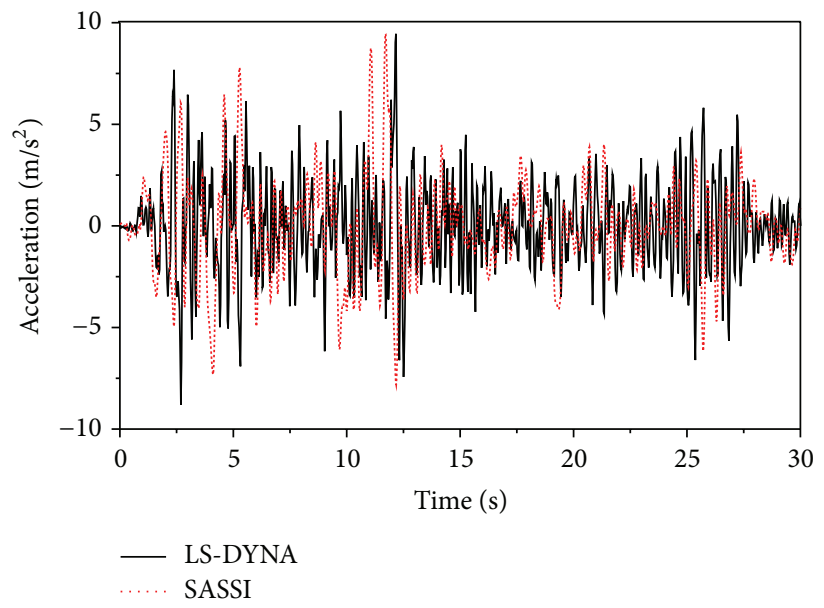

FIGURE 4: Structural roof acceleration histories of LS-DYNA and SASSI.

The total number of elements in the model URBAN11 (SSI) system is $1,271,193$. The total number of elements in the model URBAN2-2 system (in which the spacing $D$ between two adjacent structures is $12 \mathrm{~m}$ ) is $1,366,598$. The total number of elements in the model URBAN4-4 system (in which the spacing $D$ between two adjacent structures is $12 \mathrm{~m}$ ) is $1,744,857$. The total number of elements in the model URBAN6-6 system (in which the spacing $D$ between two adjacent structures is $12 \mathrm{~m}$ ) is $2,199,417$. The total number of elements in the model URBAN10-10 system (in which the spacing $D$ between two adjacent structures is $12 \mathrm{~m}$ ) is $3,307,202$.

To confirm the reliability of the ANSYS/LS-DYNA FE model, the time-history responses of structure in the URBAN1-1 (SSI) system computed by LS-DYNA are compared with the responses computed by the computer code SASSI [40], which is specialized for SSI analysis and depends on the substructuring subtraction method. The FE model of the structure in SASSI is shown in Figure 3 (in SASSI, the site is assumed to consist of horizontal soil layers overlying a uniform half-space; the soil finite elements need not be constructed). The structural roof acceleration responses calculated by LS-DYNA and SASSI are plotted in Figure 4. Note that, in SASSI, all assumptions about the damping coefficient, element size, artificial boundary, and other factors can be avoided; the coincidence of the LS-DYNA results with the SASSI results demonstrates that the parameter values are reasonable.

\section{Problem Parameters}

We assume that the urban area, which is located at area $\left[\left(-L_{1} / 2, L_{1} / 2\right),\left(-L_{2} / 2, L_{2} / 2\right)\right]$, contains $N_{1} \times N_{2}$ structures. If the structures are uniformly distributed and $D$ is the spacing between two adjacent structures (edge to edge), then $L_{1}=$ $(B+D) \times N_{1}, L_{2}=(B+D) \times N_{2}$, where $B$ is the width of the structure. The semi-infinite space that represents the earth is defined as $\Omega$, and the infinite plane that represents the ground 


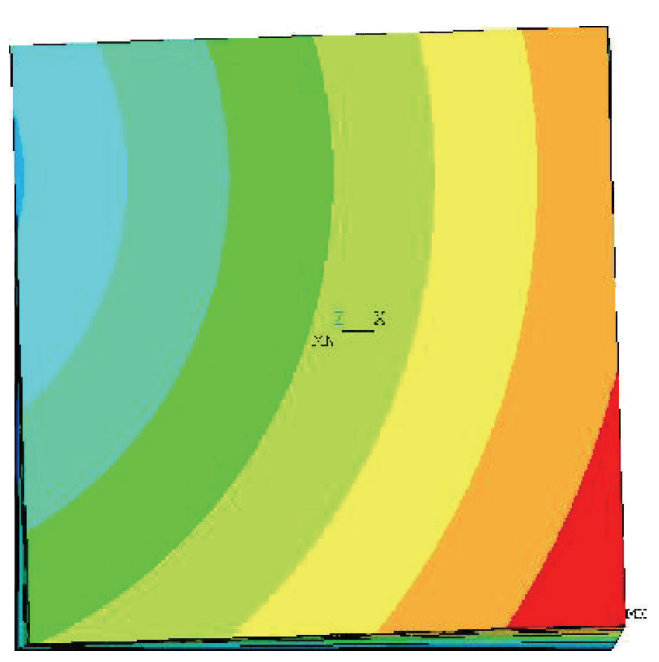

(a) Free field system

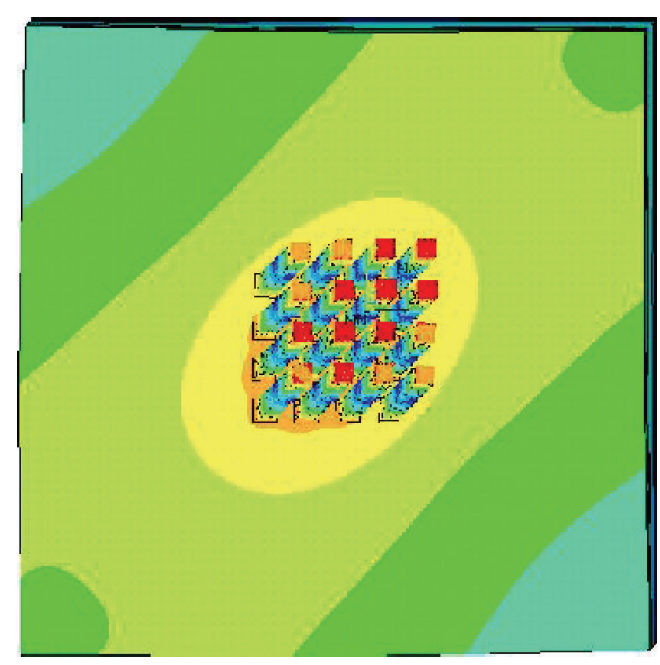

(c) URBAN4-4 system $(\bar{D}=0.5)$
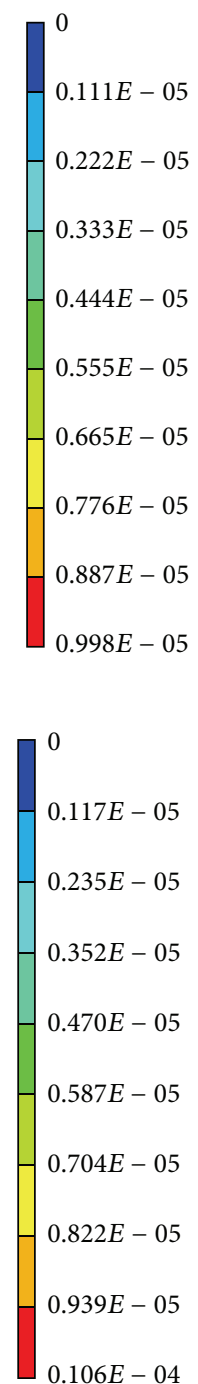

$0.106 E-04$

(a)

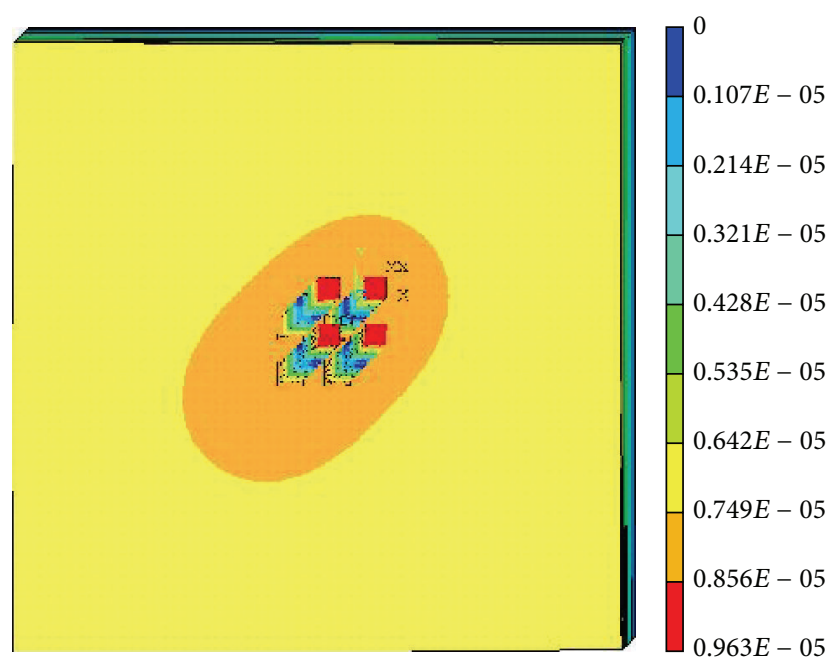

(b) URBAN2-2 system $(\bar{D}=0.5)$

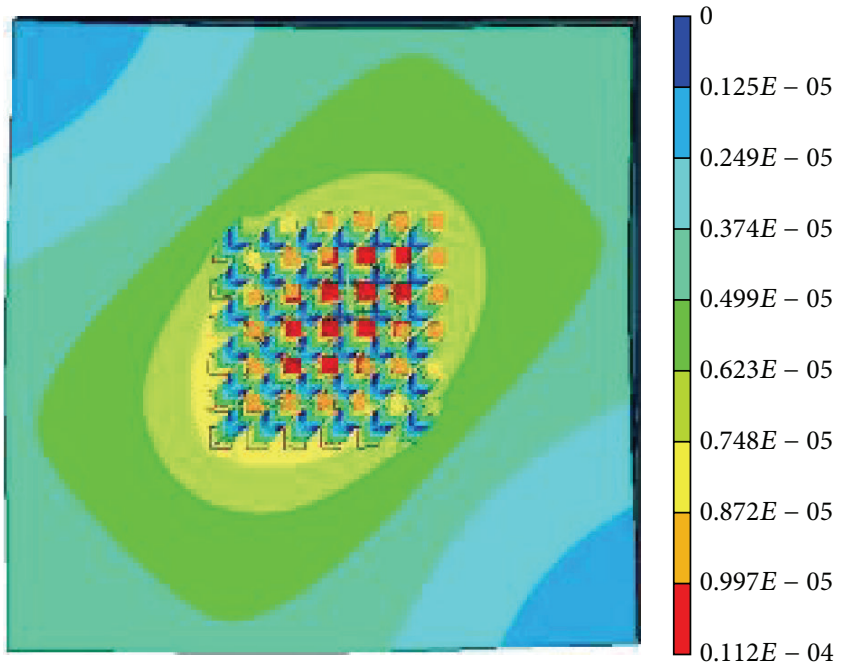

(d) URBAN6-6 system $(\bar{D}=0.5)$

FIgURE 5: System First mode shapes.

surface is $\Gamma\left(\Gamma=\Omega_{z=0}\right)$. We denote the ground surface inside the urban area by $\Gamma^{\text {inside }}\left(\Gamma^{\text {inside }}=\Gamma_{x \subset\left(-L_{1} / 2, L_{1} / 2\right), y \subset\left(-L_{2} / 2, L_{2} / 2\right)}\right)$ and the ground surface outside the urban area by $\Gamma^{\text {outside }}$ $\left(\Gamma^{\text {outside }}=\Gamma_{x \subset\left(\left(-\infty,-L_{1} / 2\right) \cup\left(L_{1} / 2, \infty\right)\right), y \subset\left(\left(-\infty,-L_{2} / 2\right) \cup\left(L_{2} / 2, \infty\right)\right)}\right)$. $\Gamma_{j}^{\text {inside }}=\Gamma_{(x, y)=\left(x_{j}, y_{j}\right)}$ is the location of structure $j$. For convenience below, the structures in the first quadrant are numbered (see Figure 2).

To provide a nondimensional formulation of the effective distance of the structural group on ground motions in a later section, we introduce the nondimensional spatial coordinates $x^{\prime}, y^{\prime}$, which are defined as $x^{\prime}=x /(B+D), y^{\prime}=y /(B+D)$. The dimensionless distance $\bar{D}$ is $D / B$.

From the system harmonic analysis, we can obtain the steady-state response of SSSI systems in the frequency domain. The amplitude of the structural base horizontal displacements is denoted by $X_{s g}$; the shaking amplitude on the surface of bedrock is denoted by $X_{0}$. Then, the transfer function $Q$ is defined as $Q=\operatorname{abs}\left\{X_{s g} / X_{0}\right\}$.

In this paper, the influence of SSSI on the horizontal seismic behavior of a structure compared with the SSI case is analyzed in terms of the influence coefficient $e_{t}$ or $e_{h}$, which is defined as $e_{t}=\left(\left(P_{\mathrm{SSSI}}-P_{\mathrm{SSI}}\right) / P_{\mathrm{SSI}}\right) \times 100 \%$ and $e_{h}=$ $\left(\left(Q_{\text {SSSI }}-Q_{\text {SSI }}\right) / Q_{\text {SSI }}\right) \times 100 \%$, where $P_{\text {SSSI }}$ and $P_{\text {SSI }}$ are the horizontal acceleration amplitude at the base of structures in SSSI system and SSI system, respectively, calculated by time domain analyses of the whole building-soil system. $Q_{\text {SSSI }}$ and $Q_{\text {SSI }}$ are the transfer function value $Q$ at the base of structures in the SSSI system and SSI system, respectively, calculated by the harmonic analysis of the whole buildingsoil system. Thus, $e_{t}$ or $e_{h}$ reflects the influence of SSSI on structures compared with SSI. $e_{t}>0$ or $e_{h}>0$ indicates that the influence of SSSI makes the structures "dangerous," and $e_{t}<0$ or $e_{h}<0$ indicates that the influence of SSSI makes 


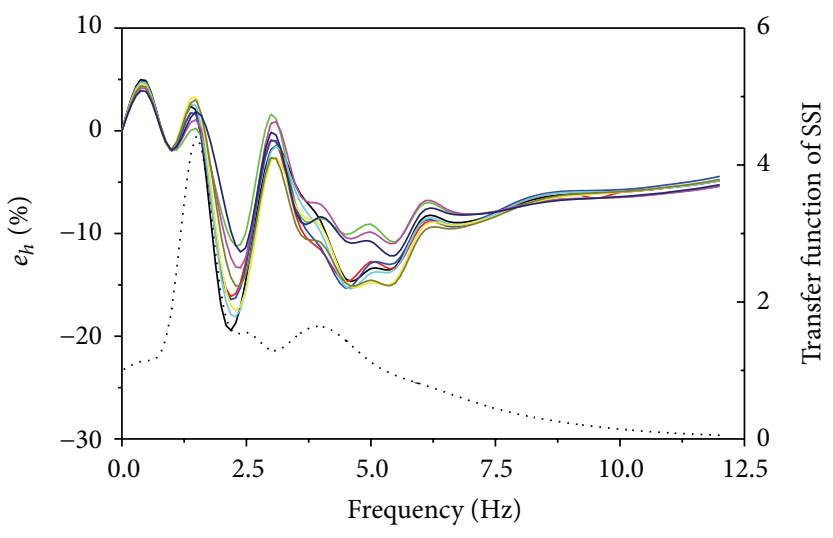

$$
\begin{aligned}
& ---e_{h} \text { of structure } 1 \text { in URBAN6-6 } \\
& ---e_{h} \text { of structure } 2 \text { in URBAN6-6 } \\
& ---e_{h} \text { of structure } 3 \text { in URBAN6-6 } \\
& ---e_{h} \text { of structure } 4 \text { in URBAN6-6 } \\
& ---e_{h} \text { of structure } 5 \text { in URBAN6-6 } \\
& ---e_{h} \text { of structure } 6 \text { in URBAN6-6 } \\
& ---e_{h} \text { of structure } 7 \text { in URBAN6-6 } \\
& ---e_{h} \text { of structure } 8 \text { in URBAN6-6 } \\
& ---e_{h} \text { of structure } 9 \text { in URBAN6-6 } \\
& \ldots . . \text { Transfer function of SSI }
\end{aligned}
$$

FIgURE 6: Interaction among structures in terms of influence coefficient $e_{h}$ (URBAN6-6, $S X, \bar{D}=0.5$ ). The solid lines are the influence coefficient $e_{h}$ of URBAN6-6 system. The dashed line is the transfer function $Q$ in the URBAN1-1 (SSI) system.

the structures "safer." $e_{t \max }$ and $e_{t \min }$ refer to the maximum and minimum values of $e_{t}$ of all structures in an individual urban area, respectively.

The seismic damage of the structure is analyzed in terms of the energy magnification factor $\beta$, which is defined as $\beta=\left(\left(E-E^{*}\right) / E^{*}\right) \times 100 \%$, where $E$ and $E^{*}$ are the structural absorbed energy in the SSSI cases and URBAN1-1 (SSI) case, respectively, which are calculated by system time domain analysis.

The energy density of a site is a parameter that reflects the global response of the site and the entire effect of the SSSI. We introduce parameter $\varphi$ to indicate the average ground surface energy density, which is defined as $\varphi=\Psi / A$, where $\Psi$ is the total ground surface energy (being calculated by system time domain analysis) in the calculated area $\Gamma^{\prime}$ and $A$ is the area of $\Gamma^{\prime}$. When $\Gamma^{\prime}=\Gamma^{\text {inside }}$, we define $\varphi$ as $\varphi_{\text {city }}^{\text {inside }}$, which represents the average ground energy density inside an urban area. In the free field case, we define $\varphi$ as $\varphi^{\text {free }}$, which represents the free field average ground energy density. The percent ratio of $\left(\varphi_{\text {city }}^{\text {inside }}-\varphi^{\text {free }}\right)$ to $\varphi^{\text {free }}$ is defined as $\alpha$ $\left(\alpha=\left(\left(\varphi_{\text {city }}^{\text {inside }}-\varphi^{\text {free }}\right) / \varphi^{\text {free }}\right) \times 100 \%\right)$, which reflects the SSSI influence on the site seismic response.

\section{Modal Response Results}

The fundamental period is an important dynamic property of structures or systems that can help predict the seismic behavior of a structure or systems during an earthquake. Modal analysis, which provides the fundamental frequencies of the SSSI system, also emphasizes the collective behavior of the structures through the modal shape. The fundamental frequencies of a structure with a fixed base, free field system, URBAN1-1 (SSI) system $(\bar{D}=0.5)$, URBAN2-2 system $(\bar{D}=$ $0.5)$, URBAN4-4 system $(\bar{D}=0.5)$, and URBAN6-6 system $(\bar{D}=0.5)$ are $0.63 \mathrm{~Hz}, 1.377 \mathrm{~Hz}, 1.374 \mathrm{~Hz}, 1.376 \mathrm{~Hz}, 1.375 \mathrm{~Hz}$, and $1.372 \mathrm{~Hz}$, respectively. As expected, the change in the number of structures modifies the fundamental frequency of the entire system slightly. Figure 5 shows the first mode shape of the free field system, URBAN2-2 system, URBAN4-4 system, and URBAN6-6 system. Both the deformations of the ground and the deformations of the independent structures are modified due to the existence of structural groups. The first model responses of downtown buildings are larger than those of buildings in periurban areas.

\section{Earthquake Response Results}

6.1. Influence of Seismic Records. Before studying the influence of seismic records, we conducted system harmonic analysis of the URBAN1-1 (SSI) system and URBAN6-6 $(\bar{D}=0.5)$ system, Figure 6 shows the transfer function $Q$ of the URBAN1-1 (SSI) system together with the influence coefficients $e_{h}$ of the URBAN6-6 $(\bar{D}=0.5)$ system. SSSI alters the transfer functions of an SSSI system compared to the SSI system and makes the transfer functions for individual structures inside the same urban area different. Comparing $e_{h}$ of individual structures reveals that between the frequencies of $1.25 \mathrm{~Hz}$ to $7.5 \mathrm{~Hz}$, the transfer functions of URBAN6-6 for individual structures vary distinctly. However, with lower or 

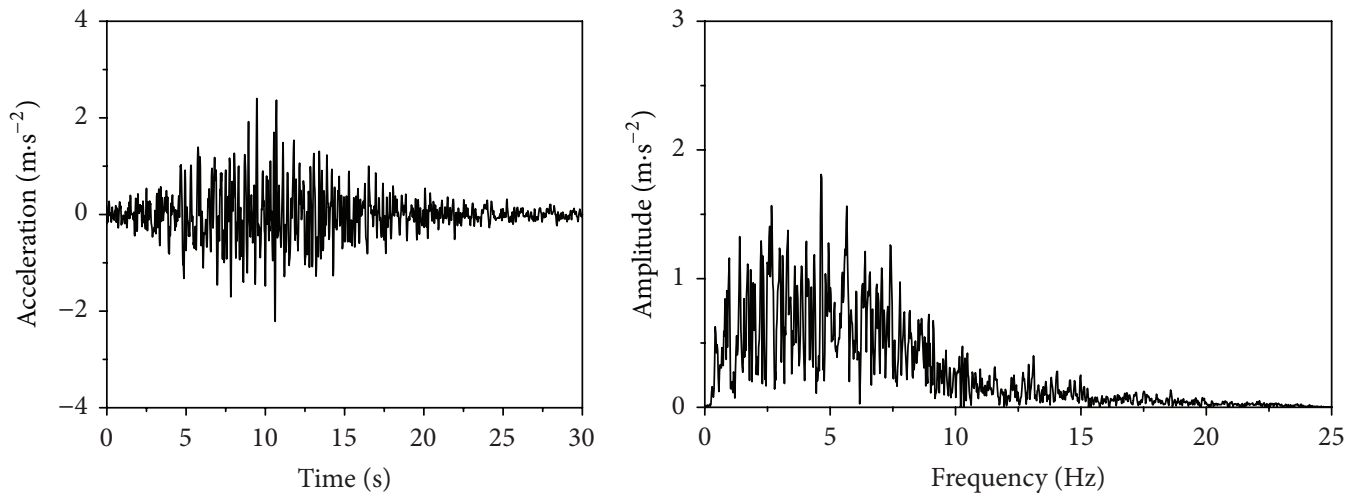

(a) MCH-000 (record type: measured bedrock wave; location: Loma Prieta; data: 1989-10-18)
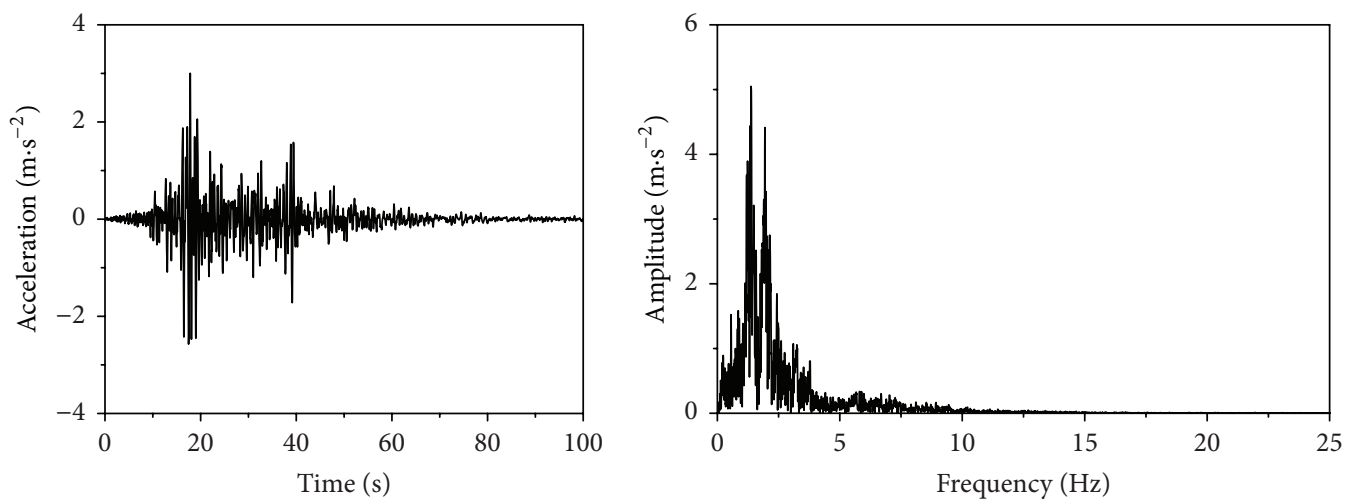

(b) CHY086 (record type: measured bedrock wave; location: Chi-Chi; data: 1999-09-20)
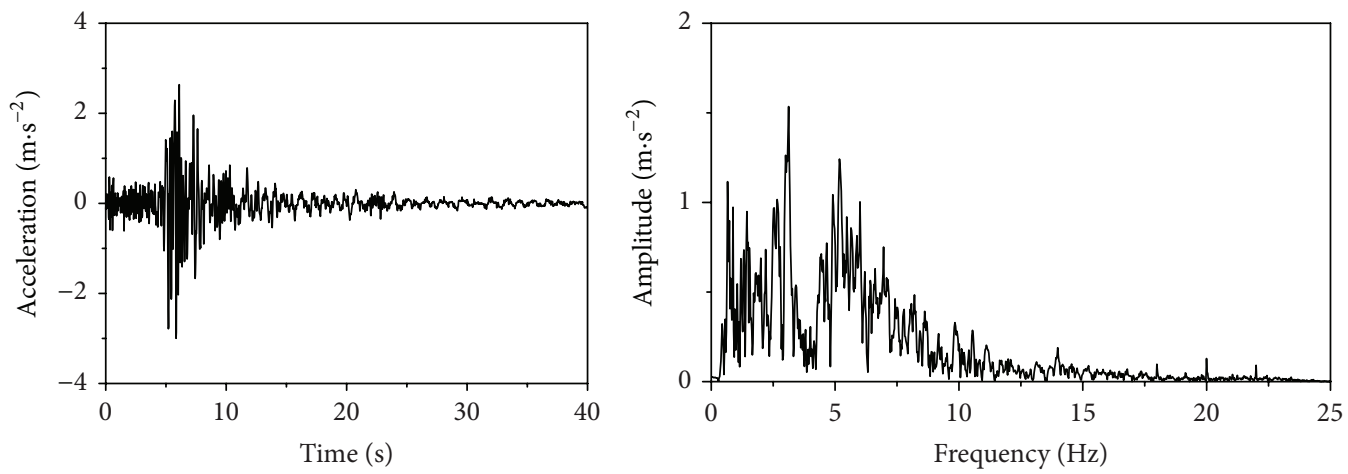

(c) PO214 (record type: measured bedrock wave; location: Livermore; data: 1980-01-24)
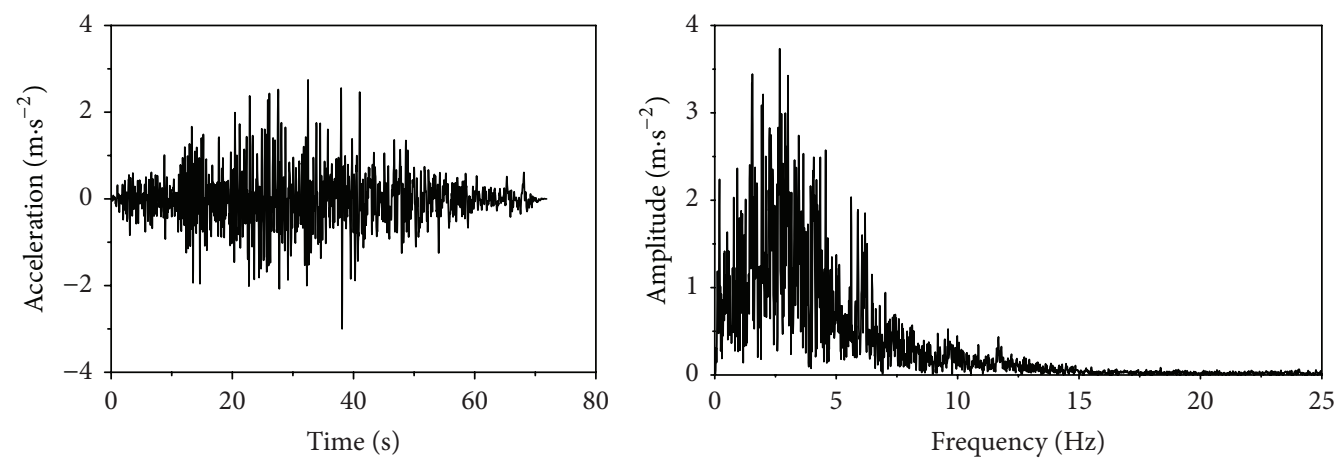

(d) TTN024 (record type: measured bedrock wave; location: Chi-Chi; data: 1999-09-20)

Figure 7: Continued. 

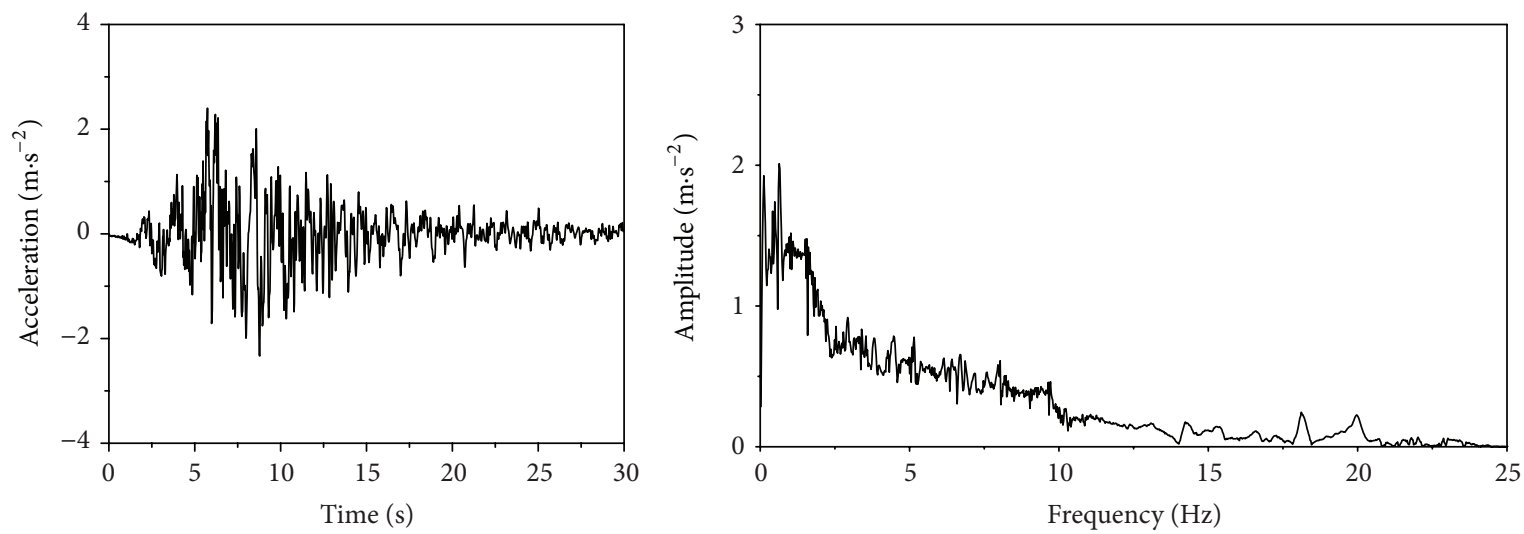

(e) SHWN1 (record type: artificial bedrock wave; location: Shanghai, China)
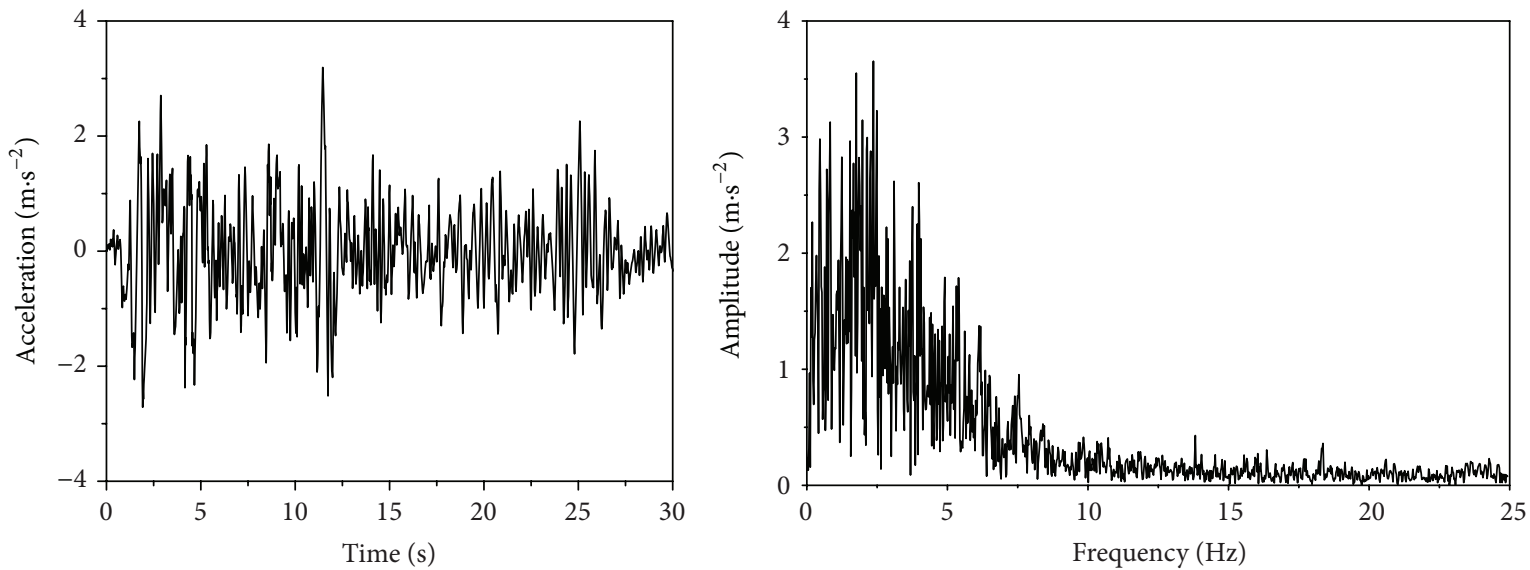

(f) El Centro (record type: measured ground wave; location: Imperial Valley; data: 1940-05-18)

FIgURE 7: Seismic wave data.

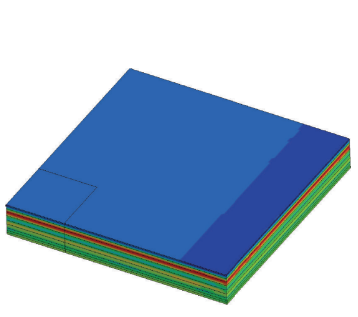

Time $=1.479 \mathrm{~s}$

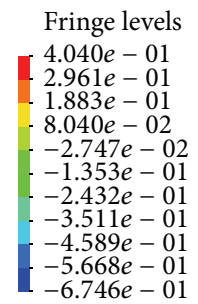

$-6.746 e-01$

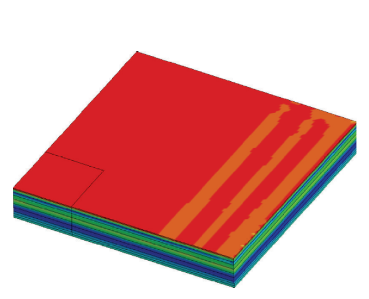

Time $=8.426 \mathrm{~s}$

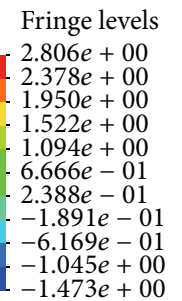

$1.045 e+00$
$-1.473 e+00$

Figure 8: Instantaneous $X$-component acceleration fields of the free field (MCH000, $S X)$. higher frequencies, the transfer function Q of URBAN6-6 for individual structures is similar.

Compared with the URBAN1-1 (SSI) system, the transfer function value of the URBAN6-6 $(\bar{D}=0.5)$ system is slightly shifted at the fundamental frequency point of the URBAN1-1 (SSI) system ( $f=1.37 \mathrm{~Hz}$; the corresponding $e_{h}$ of the URBAN6-6 system at $f=1.37 \mathrm{~Hz}$ is no greater than $3 \%)$. However, for the other frequencies, $e_{h}$ of URBAN66 system can vary $25 \%$ from nearly $-20 \%$ to $5 \%$. More specifically, the SSSI slightly aggravates the transfer function $Q$ at low frequencies $(f \leq 1.75 \mathrm{~Hz})$ and significantly mitigates the transfer function $Q$ at high frequencies $(f>1.75 \mathrm{~Hz})$. Thus, we deduce that normal seismic waves may mitigate the structural seismic response when accounting for the SSSI, and seismic waves with long periods are unlikely to mitigate the structural seismic response significantly (they may even lead to stronger shaking on structures).

In the system time domain analyses, four measured records of bedrock ground motion (MCH-000, CHY086, PO214, and TTN024), one artificial seismic wave (SHWN1), and one frequently used wave (El Centro) were selected. The waves, whose amplitudes were adjusted to $0.30 \mathrm{~g}$, were all 


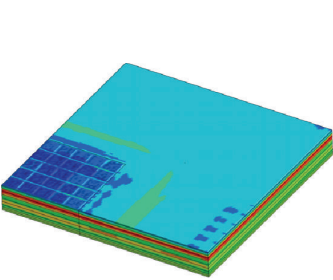

Time $=1.479 \mathrm{~s}$

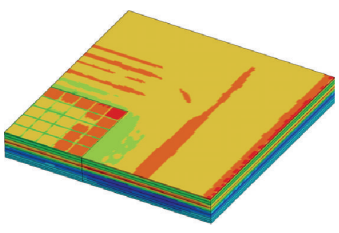

Time $=12.05 \mathrm{~s}$

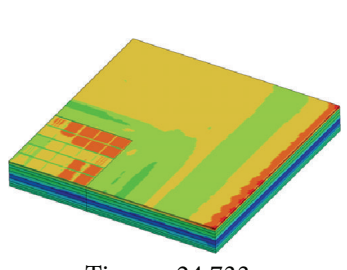

Time $=24.733 \mathrm{~s}$

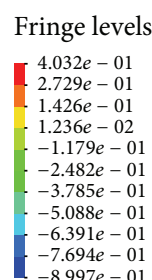

$-8.997 e-01$

Fringe levels

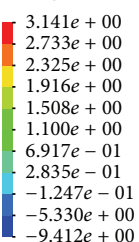

$-5.330 e+00$

Fringe levels

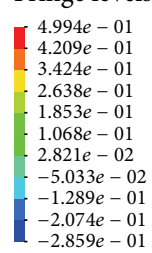

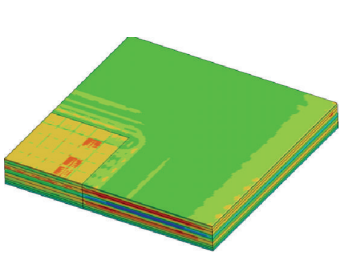

Time $=3.896 \mathrm{~s}$

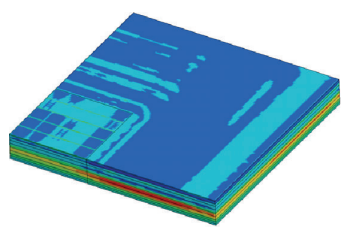

Time $=17.486 \mathrm{~s}$

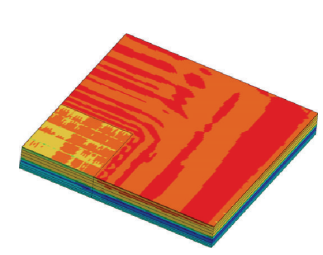

Time $=27.451 \mathrm{~s}$

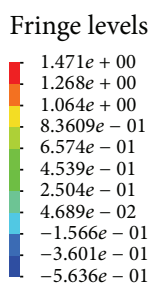

$-5.636 e-01$

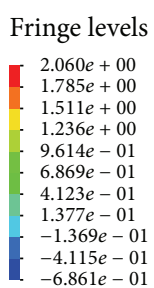

$-6.861 e-01$

Fringe levels

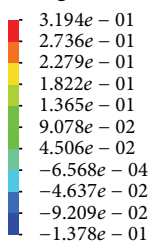

$-1.378 e-01$

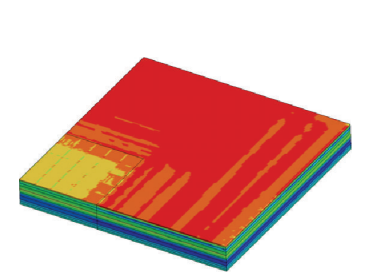

Time $=8.426 \mathrm{~s}$

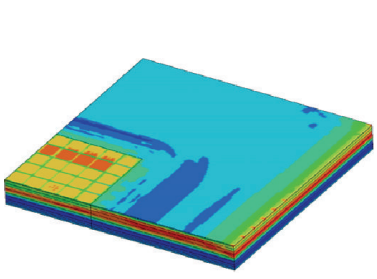

Time $=19.600 \mathrm{~s}$

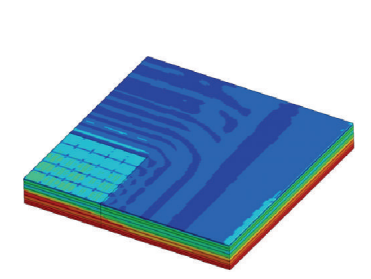

Time $=29.867 \mathrm{~s}$
Fringe levels

$2.815 e+00$

$2.386 e+00$

$1.957 e+00$

$1.529 e+00$

$1.100 e+00$

$6.717 e-01$

$-1.855 e-01$

$-6.141 e-0$

$-1.043 e+00$

Fringe levels

$1.050 e+00$

$9.159 e-01$

$7.816 e-01$

$6.474 e-01$
$5.131 e-01$
$3.789 e-01$

$5.131 e-01$
$3.789 e-01$ $3.789 e-01$
$2.447 e-01$ $1.104 e-01$ $-2.382 e-02$
$-1.581 e-01$ $-1.581 e-01$

Fringe levels

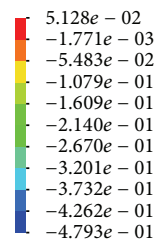

FIGURE 9: Instantaneous $X$-component acceleration fields of the URBAN10-10 system (1/4 FE model, $\bar{D}=0.5, \mathrm{MCH} 000, S X)$.

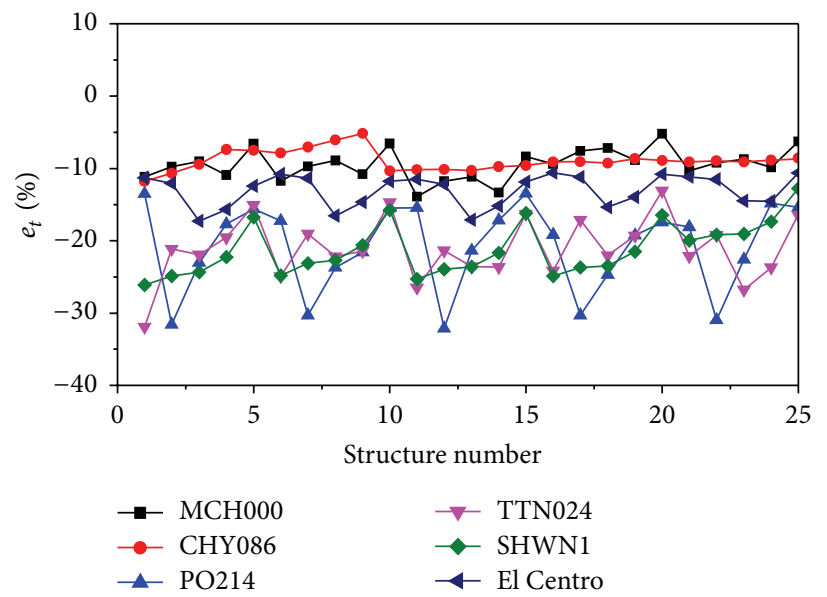

FIGURE 10: Interaction among structures in terms of influence coefficients $e_{t}$ for different incident waves $(\mathrm{URBAN10}-10, \bar{D}=0.5, S X)$.

vertically incident $\mathrm{S}$ waves. The corresponding acceleration time histories, Fourier spectra, and record data are shown in Figure 7.

The $X$-component acceleration fields in the first quadrant of the free field system and URBAN10-10 $(\bar{D}=0.5)$ system under motion produced by $\mathrm{MCH} 000(S X)$ are shown in Figures 8 and 9 (1/4 FE model), respectively. The acceleration instantaneous snapshots indicate that the disturbance of the waves radiated from the structures, and the modification to the ground motions due to SSSI can be clearly identified. The transmission of waves, which were generated from the lateral boundary, is limited and has no influence on the anticipated "urban area." In the free field, as expected, the soil acceleration is horizontally layered, whereas, in URBAN1010 , a surface-wave train is emitted from the urban area and propagates outward. In URBAN10-10, at the beginning of the earthquake, the nonuniform ground motion distribution occurs in a limited area inside and around the urban area. Over time, the SSSI influence area expands and the nonuniform degree increases. The modifications induced by the SSSI inside an urban area also contaminate the ground motion outside the urban area. Finally, the ground acceleration is apparently nonuniform, particularly inside the urban area. Because the SSSI is more noticeable in the later part of 


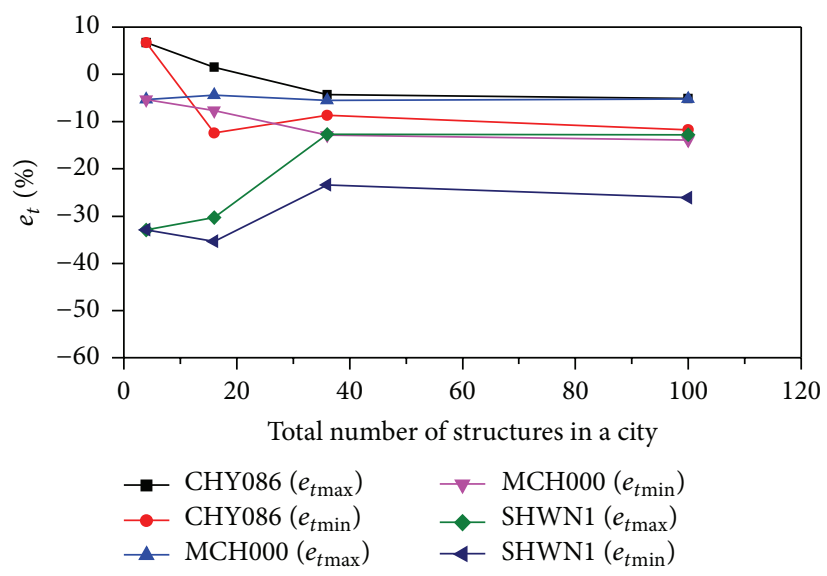

FIGURE 11: Interaction between structures in terms of influence coefficients $e_{t \max }$ and $e_{t \min }$ with respect to the number of structures in the urban area $(\bar{D}=0.5, S X)$.

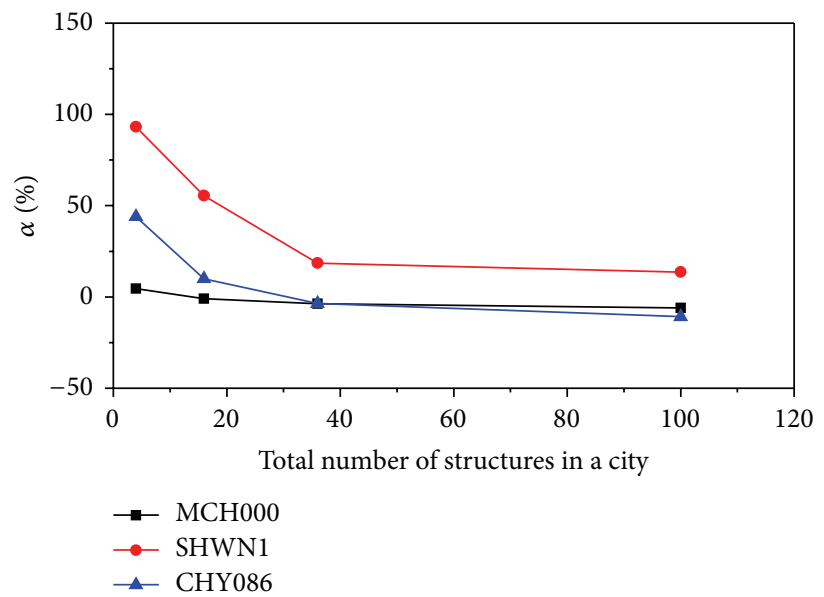

Figure 12: Site seismic response in terms of coefficient $\alpha$ with respect to the number of structures in the urban area $(\bar{D}=0.5, S X)$.

earthquakes, we conjecture that long-duration seismic waves will make the SSSI influence more noticeable.

Figure 10 shows the influence of SSSI in terms of the influence coefficients $e_{t}$ of the URBAN10-10 $(\bar{D}=0.5)$ system under six $S$ waves that produce motion along the $X$-axis. Clearly, the value of $e_{t}$ is negative, and the absolute value is within approximately $35 \%$ for the 6 seismic waves. For each wave, $e_{t}$ periodically changes with respect to the structure number. This feature coincides with the phenomena observed in 1976 for the earthquake in Friuli, Italy, which will be further discussed in Section 6.2.

6.2. Influence of the Size of the Structural Group. This section discusses the influence of the number of structures inside an urban area on the SSSI. Figure 11 shows the $e_{t \max }$ and $e_{t \text { min }}$ of square arrangement urban areas, with the number of structures ranging from 1 to $100(\bar{D}=0.5)$. For a number of structures between 1 and 36 , both $e_{t \max }$ and $e_{t \min }$ fluctuate for individual excited waves. From 36 onward, $e_{t \max }$ and $e_{t \min }$ remain stable.
The influence coefficients $\alpha$, which reflect the SSSI influence on the site seismic response, are plotted in Figure 12. In the problem defined, the SSSI increases the average ground energy density inside an urban area with respect to that in a free field. At the beginning, $\alpha$ is up to nearly $100 \%$ in the most distinct case (SHWN1). As the size of the structural group increases, $\alpha$ decreases for all excited waves. When the number of structures is greater than 36 , the decreasing rate becomes negligible. For seismic waves MCH000 and CHY086, $\alpha$ tends to be zero. Because structures inside an urban area will definitely consume energy during an earthquake, the balance of the total absorbed energy inside an urban area reflects the reduction of ground seismic responses at locations between structures, which can be more clearly seen in Figures 15-18.

Figure 13 displays the total absorbed energy of individual structures in URBAN2-2, URBAN4-4, URBAN6-6, and URBAN10-10 under wave MCH000, which produces motion along the $X$-axis. Compared with URBAN1-1 (SSI), SSSI decreases the structural total absorbed energy. This decrease in energy is consistent with several previous numerical studies [25, 30] and instrumental results [29]. Moreover, 


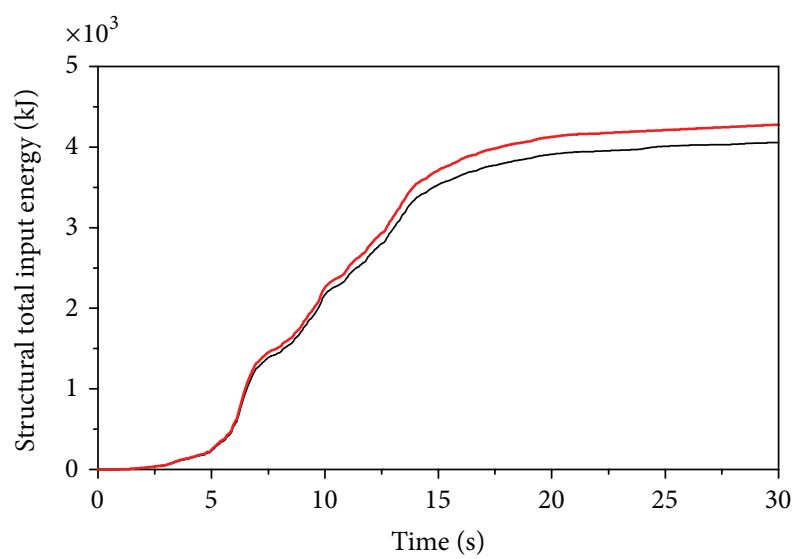

- Structure in URBAN1-1 (SSI)

(a) URBAN2-2 $(\bar{D}=0.5)$

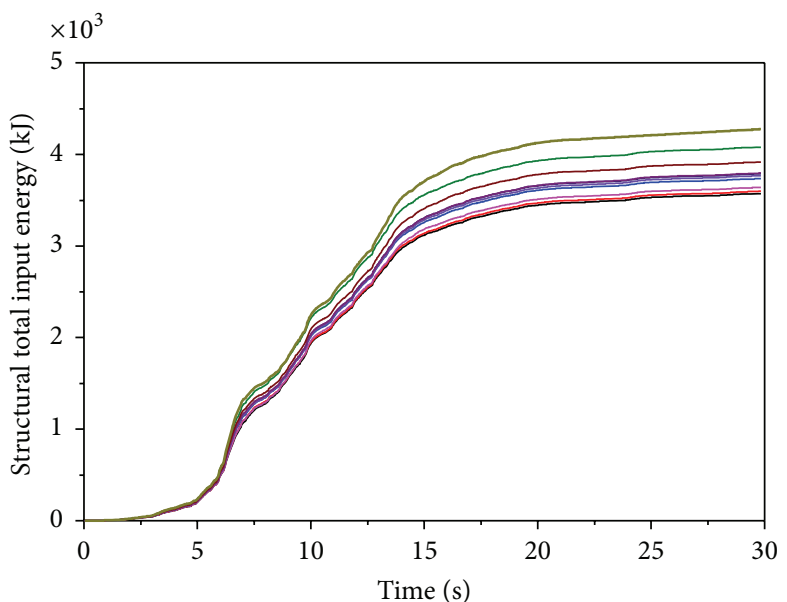

$\begin{array}{rr}\text { - Structure } 1 \text { in URBAN6-6 } & \text { Structure } 6 \text { in URBAN6-6 } \\ \text { - Structure } 2 \text { in URBAN6-6 } & \text { Structure } 7 \text { in URBAN6-6 } \\ \text { Structure } 3 \text { in URBAN6-6 } & - \text { Structure } 8 \text { in URBAN6-6 } \\ \text { - Structure } 4 \text { in URBAN6-6 } & - \text { Structure } 9 \text { in URBAN6-6 } \\ \text { Structure } 5 \text { in URBAN6-6 } & - \text { Structure in URBAN1-1 (SSI) }\end{array}$

(c) URBAN6-6 $(\bar{D}=0.5)$

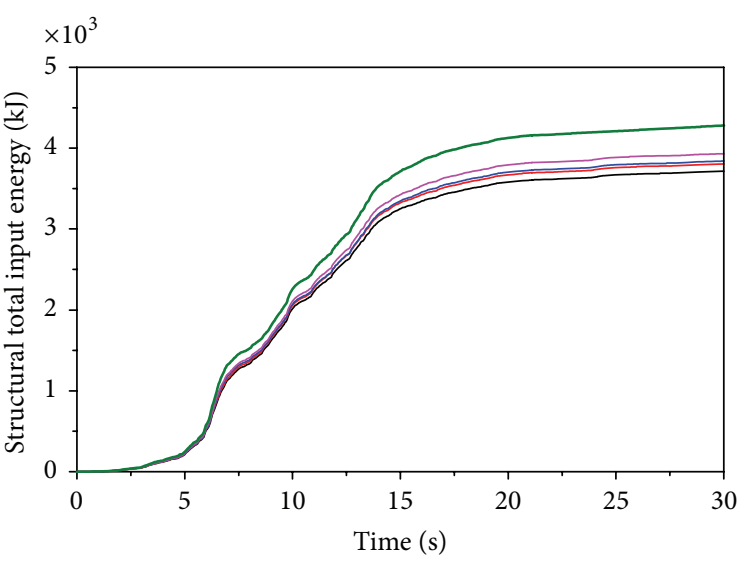

$\begin{array}{ll}\text { - Structure } 1 \text { in URBAN4-4 } & - \text { Structure } 4 \text { in URBAN4-4 } \\ - \text { Structure } 2 \text { in URBAN4-4 } & - \text { Structure in URBAN1-1 (SSI) } \\ \text { Structure } 3 \text { in URBAN4-4 }\end{array}$

(b) URBAN4-4 $(\bar{D}=0.5)$

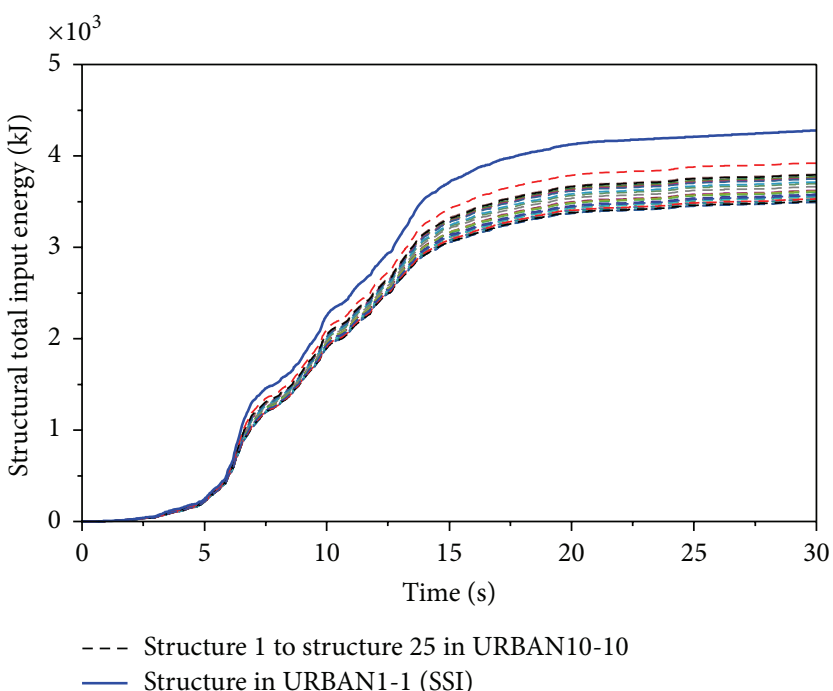

(d) URBAN10-10 $(\bar{D}=0.5)$

FIGURE 13: Structural total absorbed energy $(\bar{D}=0.5, \mathrm{MCH} 000, S X)$.

the total absorbed energy of individual structures in the same urban area varies: buildings located in the urban fringe are subjected to slightly heavier shaking than downtown buildings (i.e., the influence of the structure-soil-structure interaction is more significant in the urban center). The plot of factor $\beta$ of individual structures in URBAN6-6 supports this relationship more clearly, as shown in Figure 14.

The presence of structural groups also modifies the intensity of ground motions. The effect of a structure on neighboring soil has two components: the kinematic effect (associated with wave diffraction on the foundation) and the inertial effect (associated with wave emission following structure vibrations). The numerical results show that when many structures are involved, the individual waves radiated by each structure will interfere (multiple interactions) and significantly modify the ground motion pattern. The distribution diagrams of the PGA in the first quadrant of arrangements URBAN1-1 $(\bar{D}=1.25)$, URBAN2-2 $(\bar{D}=1.25)$, URBAN4-4 $(\bar{D}=1.25)$, and URBAN6-6 $(\bar{D}=1.25)$ under seismic wave El Centro $(S X)$, are shown in Figures 15-18. In the right boundary of every case, the influence of reflection waves caused by the artificial boundary is clear. The reflected waves, as expected, dissipate rapidly along their propagation and have no effect on the seismic response in the urban area. In Figures 15-18, four features can be observed. (i) The entire effect of the SSSI decreases the PGA, as concluded by 


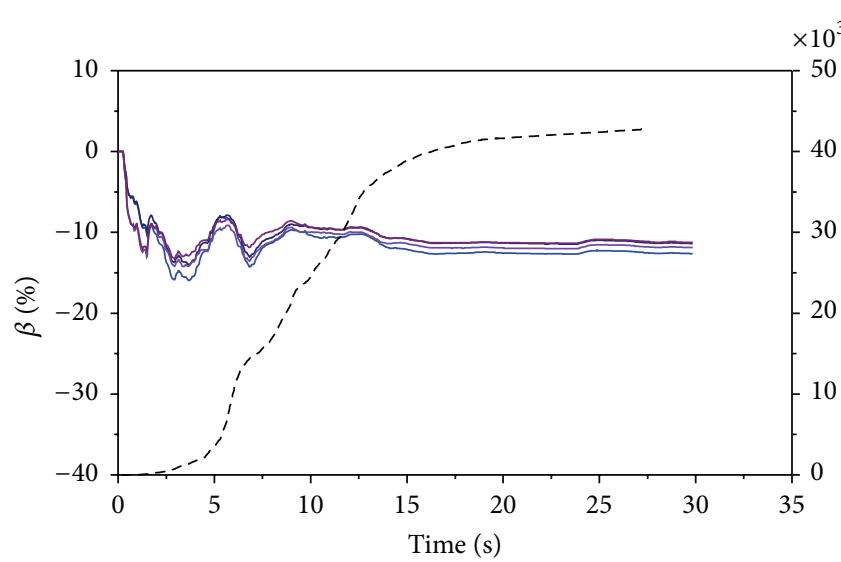

$\begin{array}{ll}\text { - Structure } 3 \text { in URBAN6-6 } & - \text { Structure } 8 \text { in URBAN6-6 } \\ \text { - Structure } 6 \text { in URBAN6-6 } & --- \text { Structure in URBAN1-1 (SSI) } \\ \text { Structure } 7 \text { in URBAN6-6 } & \end{array}$

(a) Structure number 3 , number 6 , number 7 , and number 8

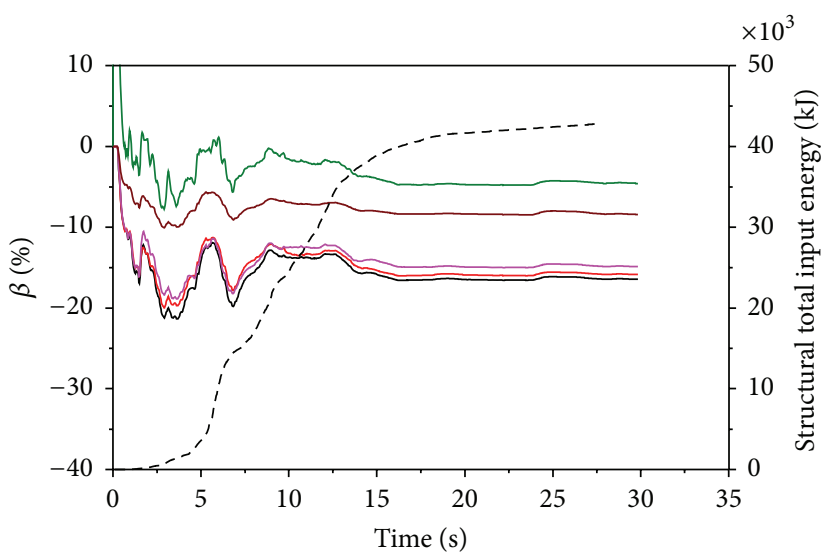

- Structure 1 in URBAN6-6 - Structure 5 in URBAN6-6

- Structure 2 in URBAN6-6 - Structure 9 in URBAN6-6

— Structure 4 in URBAN6-6 - - - Structure in URBAN1-1 (SSI)

(b) Structure number 1 , number 2 , number 4 , number 5 , and number 9

FIGURE 14: Interaction among structures in terms of influence coefficient $\beta$ (URBAN6-6, $\bar{D}=0.5, \mathrm{MCH} 000, \mathrm{SX}$ ). The solid lines are the influence coefficient $\beta$ of structures in URBAN6-6. The dashed line is the structural total absorbed energy in the URBAN1-1 (SSI) case.

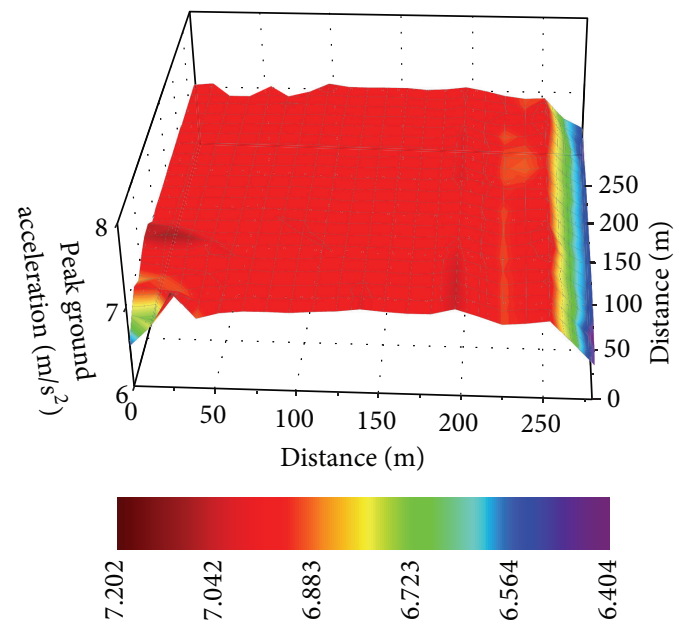

FIgURE 15: Peak ground acceleration distribution of URBAN1-1 (1/4 FE model, $\bar{D}=1.25$, El Centro, $S X)$.

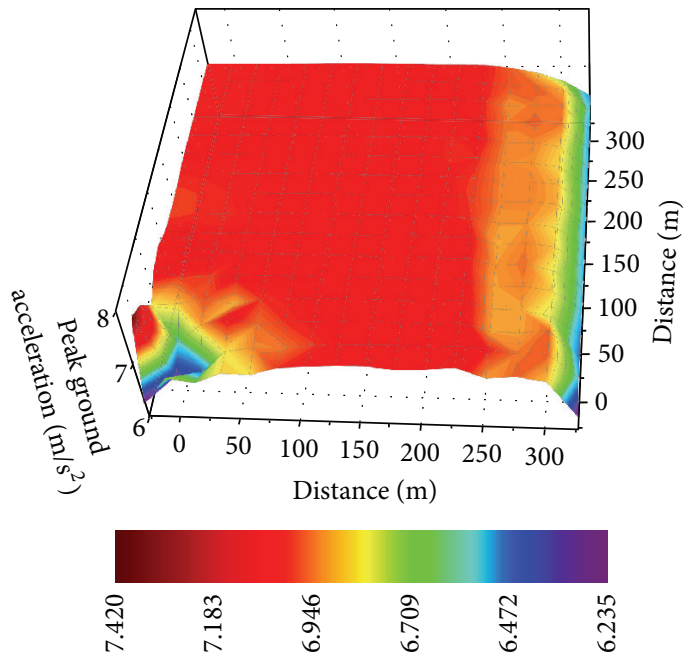

Figure 16: Peak ground acceleration distribution of URBAN2-2 (1/4 FE model, $\bar{D}=1.25$, El Centro, $S X)$. 


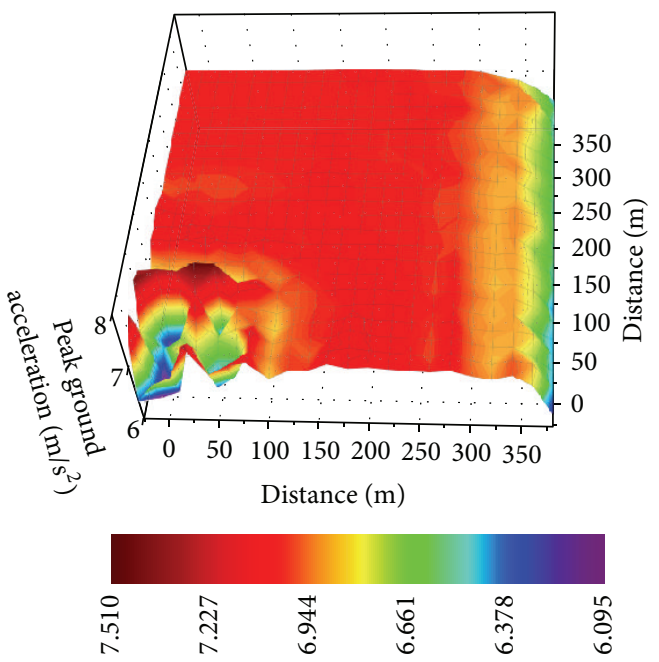

FIGURE 17: Peak ground acceleration distribution of URBAN4-4 (1/4 FE model, $\bar{D}=1.25$, El Centro, $S X)$.

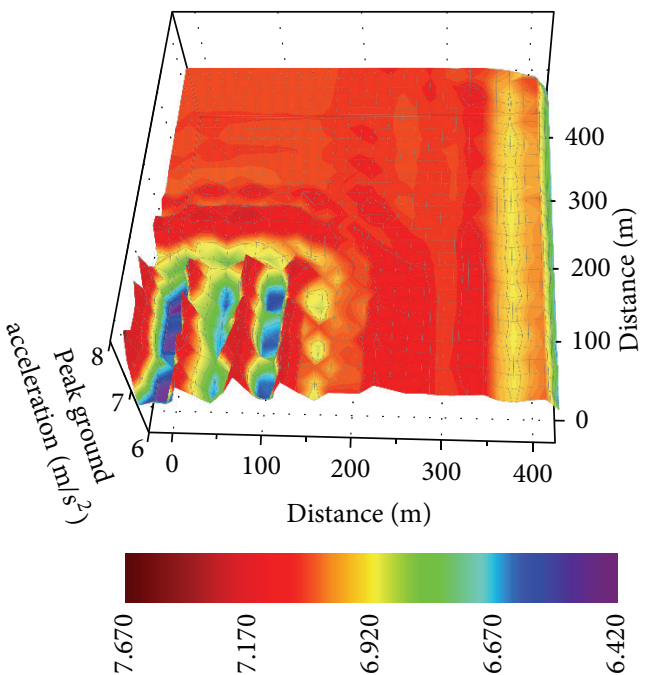

Figure 18: Peak ground acceleration distribution of URBAN6-6 (1/4 FE model, $\bar{D}=1.25$, El Centro, $S X)$.

many other studies. (ii) The existence of structural groups decreases the PGA at structure locations, and the ground motions at building locations change with alternating peaks. (iii) The PGA is relatively higher at locations between structures and even higher than the PGA of the free field at certain locations. This increase can be ascribed to the radiation and intervention of waves: waves that reflect from structures take energy away and dissipate them at locations between structures. (iv) Outside of the urban area, there is a special area where the ground motions are larger than those at other suburban areas. These nonuniform distribution features of the ground motion are evocative of the phenomena observed during earthquakes in certain districts in Mexico City.

The feature of alternating peaks at building locations is consistent with the phenomenon observed in one of the largest earthquakes in Italy, that is, the 1976 earthquake in the Friuli region. A photograph taken in the epicentral region in 1976 (Figure 19) shows a surprisingly "regular" (periodic) damage distribution [41]: the adjacent structures exhibit fully alternating mechanical behavior, that is, completely collapsed, almost undamaged, completely collapsed, almost undamaged, and so forth. This alternating "collapsed-undamaged" pattern is repeated further. Researchers explained this phenomenon by hypothesizing that part of the seismic energy that was transmitted to the structures was retransferred back into the neighborhoods through multiple interactions.

To understand the effective distance of SSSI, the PGA distribution in the first quadrant of cases URBAN2-2, URBAN44 , and URBAN6-6 with respect to the nondimensional spatial coordinates $x^{\prime}$ and $y^{\prime}$ is shown in Figures 20-22. In every figure, the PGA values along the model sections that are parallel to the $X$-axis are drawn on top of the figure; the PGA values along the model sections parallel to the $Y$-axis are drawn on the right of the figure. The nondimensional urban widths of URBAN2-2, URBAN4-4, and URBAN6-6 are 


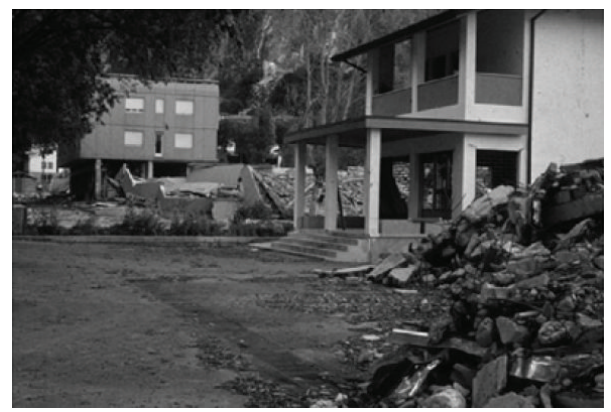

FIGURE 19: Structural damage caused by the 1976 earthquake in Friuli, Italy (photograph courtesy of Professor H. P. Rossmanith in Vienna).
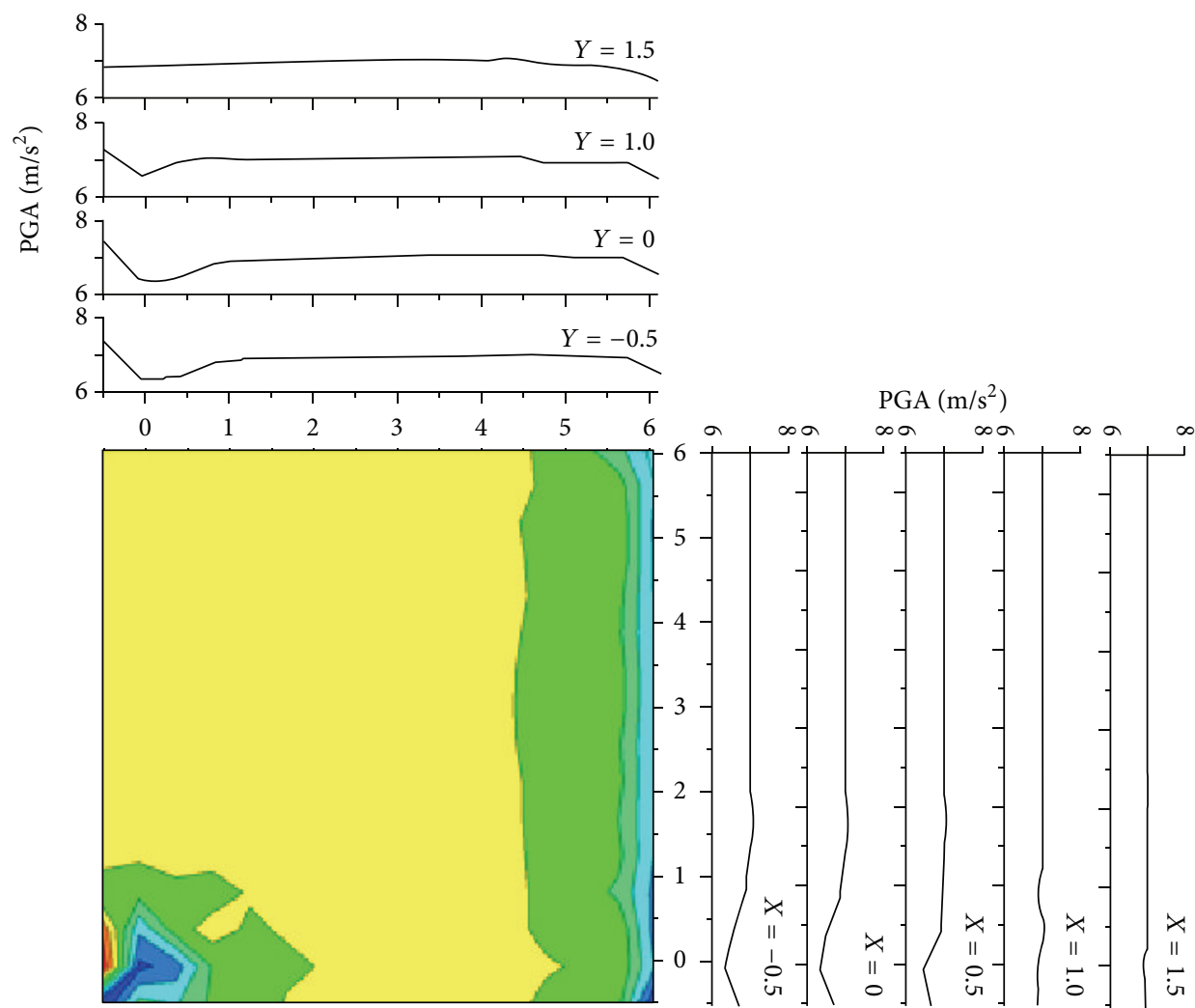

Figure 20: Peak ground acceleration distribution of URBAN2-2 with respect to nondimensional spatial coordinates $(1 / 4 \mathrm{FE}$ model, $\bar{D}=1.25$, El Centro, $S X$. The structure location is $(0,0)$. The urban nondimensional width is 2.0 ; the nondimensional effective width of the structural group parallel to the excitation is 5.0; the nondimensional effective width of the structural group perpendicular to the excitation is 3.0).

2.0, 4.0, and 6.0, respectively. The nondimensional effective widths (the overall effective width, including the urban width and the bilateral effective length outside the urban area; the definition of the nondimensional effective widths in the rest of this paper is as same as here) of the structural group parallel to the excitation of URBAN2-2, URBAN4-4, and URBAN66 are 5.0, 7.0, and 11.0, respectively. The nondimensional effective widths of the structural group perpendicular to the excitation of URBAN2-2, URBAN4-4, and URBAN6-6 are 3.0, 5.0, and 9.0, respectively. We can then observe the following. (1) The distance of the urban effect in the direction parallel to the excitation (the $X$-direction) is larger than that in the direction perpendicular to the excitation (the $Y$ direction). Of course, the interference between the soil and structures, which caused the SSSI effect, is greater in the direction parallel to the excitation. (2) The effective width of the structural group is associated with the urban width. For the problem examined in this paper, in the direction parallel to the shaking, the effective width of the structural group is approximately 2.0 times that of the urban width; in the direction perpendicular to the shaking, the effective width of the structural group is approximately 1.5 times that of the urban width.

6.3. Influence of the Structural Group Arrangement. For structural groups with different arrangements, the influence of SSSI on structures in terms of influence coefficients 

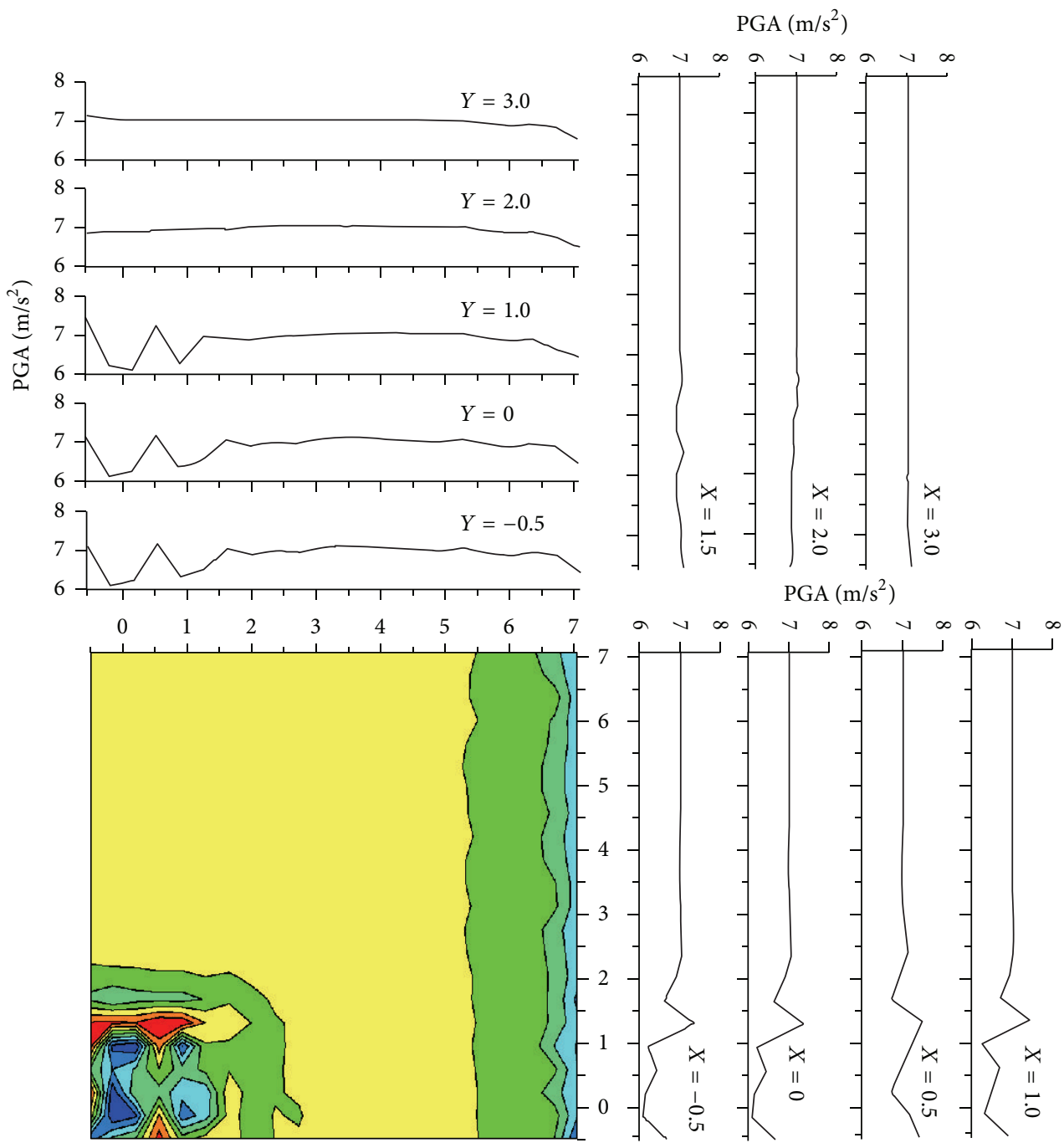

FIGURE 21: Peak ground acceleration distribution of URBAN4-4 with respect to nondimensional spatial coordinates $(1 / 4 \mathrm{FE}$ model, $\bar{D}=1.25$, El Centro, $S X$. The structure location is $(0,0),(0,1),(1,0)$, and $(1,1)$. The urban nondimensional width is 4.0 ; the nondimensional effective width of the structural group parallel to the excitation is 7.0; the nondimensional effective width of the structural group perpendicular to the excitation is 5.0).

$e_{t}(\bar{D}=0.5)$ is presented in Figure 23. $e_{t \max }$ and $e_{t \min }$ of individual arrangement are plotted in Figure 24. In those cases, seismic waves are vertically incident on the surface of bedrock (depth $=60 \mathrm{~m}$ ), either parallel to the $X$-axis or $Y$ axis.

The influence coefficients $e_{t}$ of URBAN6-6 and URBAN10-10 with square arrangements under shaking $S X$ or $S Y$ are shown in Figures 23(a) and 23(b), respectively. These figures show that along the shaking direction, the influence of the SSSI on individual structures is alternating; the "regular" (periodic) damage pattern in Figure 19 appears again. Along the direction perpendicular to the shaking, the alternating phenomenon is not as noticeable.

The influence coefficients $e_{h}$ of the URBAN6-10 system under incident shaking ( $S X$ or $S Y$ ) are shown in Figure 25. Compared with the influence coefficients $e_{h}$ of the URBAN66 system in Figure 6, it can be seen that the influence of SSSI varies from one arrangement to another and for different shaking directions, particularly when the excitation frequency is high.

6.4. Influence of the Distance between Structures. The influence of the distance between structures on the interaction is investigated in Figure 26 for URBAN6-6 under S waves $\mathrm{MCH} 000$ and SHWN1, which produce motion along the $X$ axis. For all structures investigated, the SSSI effect generally decreased as the distance between structures increased, with fluctuations, and not monotonously. Clearly, with the increase in distance, the energy of a scattered wave from a structure decreases, and the interaction between structures disappears gradually. When $\bar{D}$ is less than 0.25 , which is equivalent to a distance of $6 \mathrm{~m}$, the influence coefficient $e_{t}$ increases to approximately $60 \%$. In addition, as the distance decreases, the range of $e_{t}$ inside the same urban is reduced. 


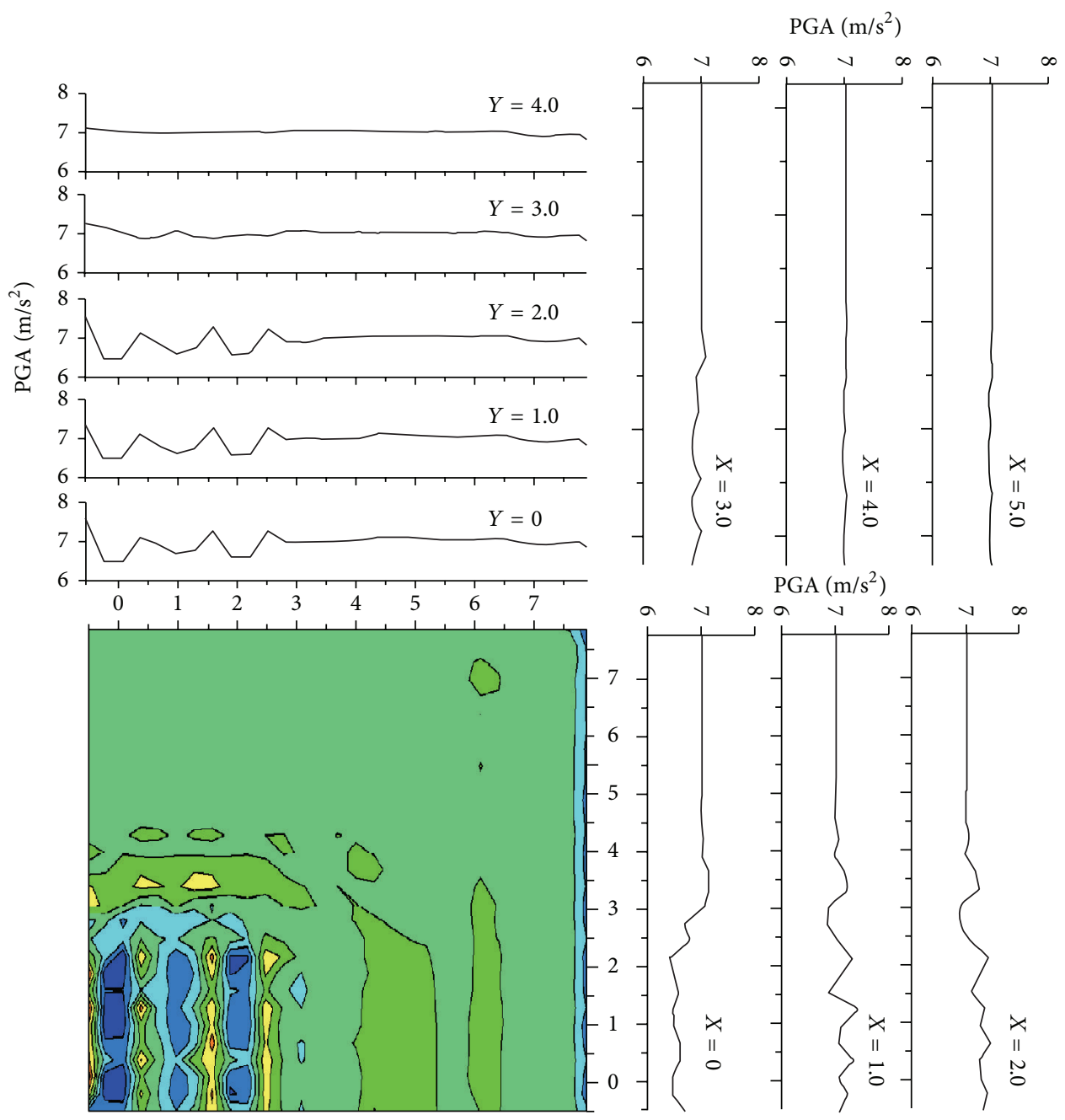

FIGURE 22: Peak ground acceleration distribution of URBAN6-6 with respect to nondimensional spatial coordinates $(1 / 4 \mathrm{FE}$ model, $\bar{D}=1.25$, El Centro, $S X$. The structure location is $(0,0),(0,1),(0,2),(1,0),(1,1),(1,2),(2,0),(2,1)$, and $(2,2)$. The urban nondimensional width is 6.0; the nondimensional effective width of the structural group parallel to the excitation is 11.0; the nondimensional effective width of the structural group perpendicular to the excitation is 9.0).

To determine the effect of the distance between structures on ground motions, the PGA distribution in the first quadrant of URBAN6-6 ( $\bar{D}=0.5)$ was plotted (see Figure $27,1 / 4$ FE model, El Centro, $S X$ ). The graph indicates that decreasing the distance between structures reduces the ground motions inside an urban area, both at building locations and at the locations between structures. In contrast to URBAN6-6 $(\bar{D}=$ 1.25 , see Figure 18$)$, URBAN6-6 $(\bar{D}=0.5)$ reacted more like an entire entity: the nonuniformity of ground motions decreases but does not disappear. Furthermore, decreasing the distance between structures does not change the influence distance of an urban area (see Figure 28), which means that the effective width of a structural group is still approximately 2.0 times that of the urban width in the direction parallel to the shaking and is still approximately 1.5 times that of the urban width in the direction perpendicular to shaking, which is similar to that when $\bar{D}=1.25$. For URBAN6-6 $(\bar{D}=0.5)$, the urban nondimensional width is 6.0 , the nondimensional effective width of a structural group parallel to the excitation is 12.0 , and the nondimensional effective width of a structural group perpendicular to the excitation is 9.0.

6.5. Influence of the Subsoil Shear Wave Velocity. An important attribute of the subsoil is the shear wave velocity. The influence coefficient $e_{t}$ of the URBAN6-6 system under vertically incident $S$ waves that produce motion along the $X$-axis, now for different shear wave velocities in every soil layer $\left(\overline{v_{s}}=n v_{s}, n=0.25,0.5,2\right)$, is presented in Figure 29. For structures built on a hard site (equivalent shear wave velocity is greater than $722 \mathrm{~m} / \mathrm{s}$ ), the influence of SSSI on the amplitude of the structural base horizontal acceleration is negligible. As the shear wave velocity decreases, not only does the SSSI influence on structural base horizontal acceleration amplitude increase, but the range of structural base horizontal acceleration amplitude inside the same urban area increases. For different site types, the SSSI 


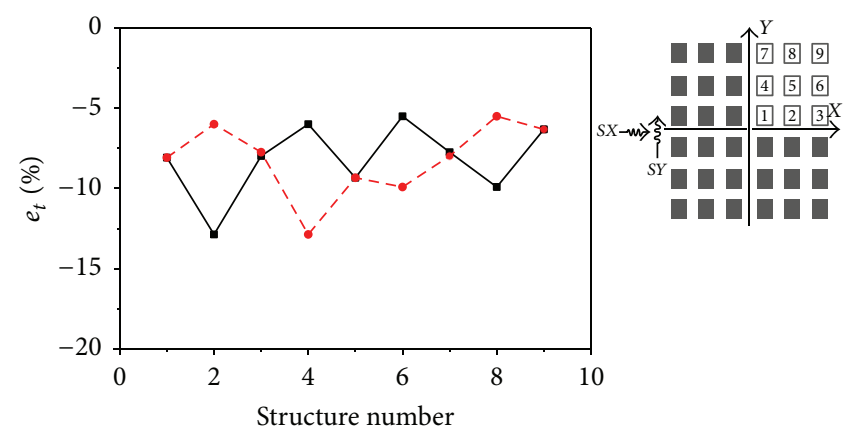

$\rightarrow$ Shaking along the $X$-axis $(S X)$

- - Shaking along the $Y$-axis (SY)

(a) URBAN6-6

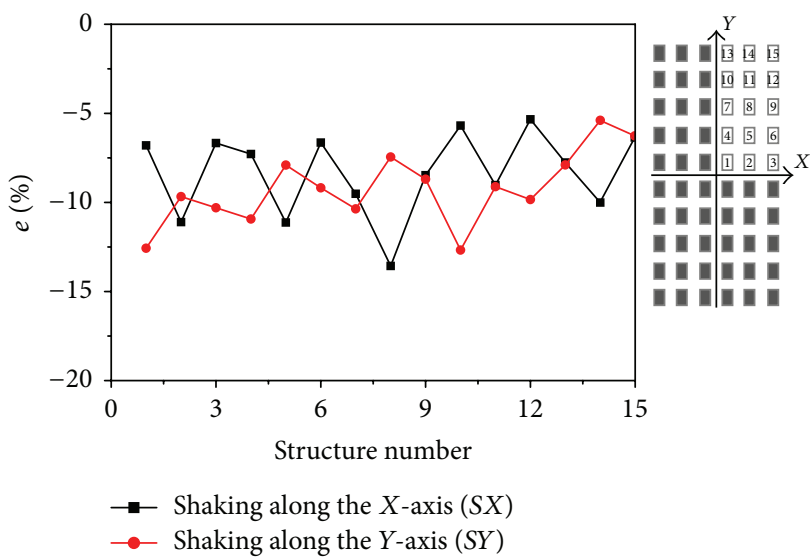

(c) URBAN6-10

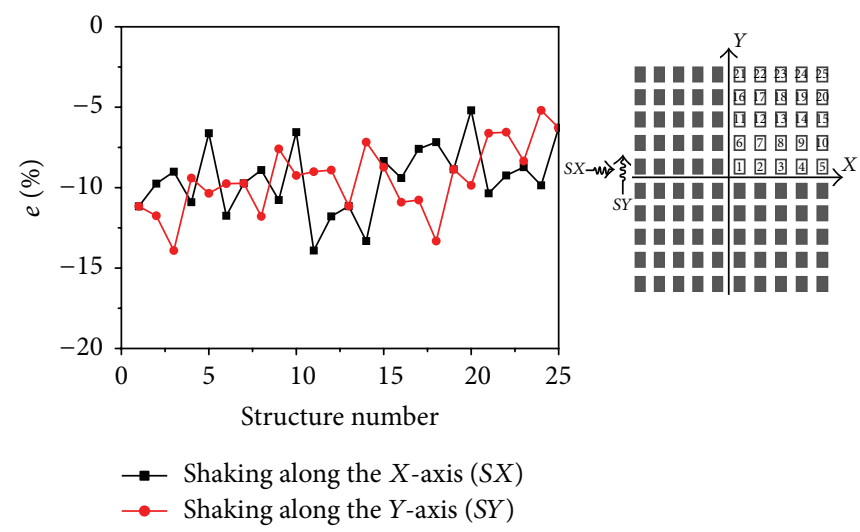

(b) URBAN10-10

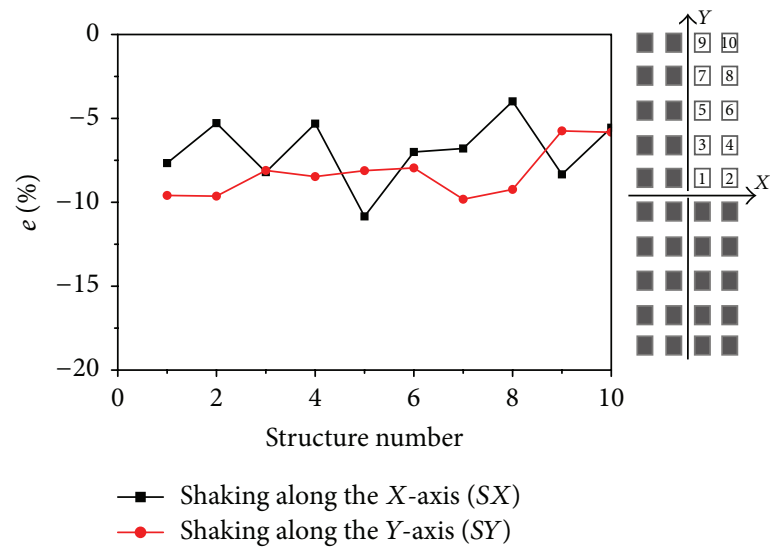

(d) URBAN4-10

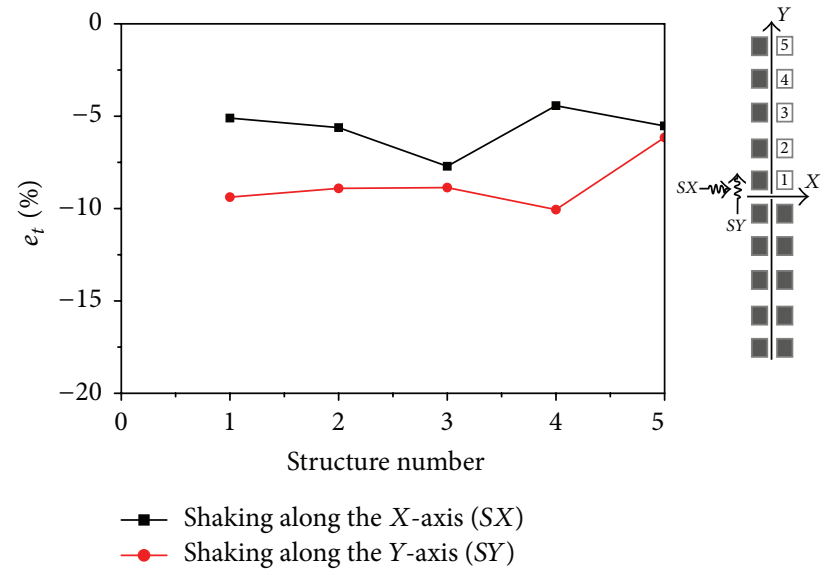

(e) URBAN2-10

FIGURE 23: Interaction among structures in terms of influence coefficient $e_{t}$ for structural groups with different arrangements $(\bar{D}=0.5$, $\mathrm{MCH} 000, S X$ or $S Y$ ). The arrangement is shown in the schematic diagram in the top-right corner.

effect can increase or decrease the structural base horizontal acceleration amplitude. For structures built on an extremely soft site (equivalent shear wave velocity is approximately $180 \mathrm{~m} / \mathrm{s}$ herein), the "beneficial" effect of the SSSI can be enormous at the same locations, whereas, at other locations, the SSSI influence is minimal. In other words, the "regular" (periodic) damage distribution is noticeable at a soft site.
The "beneficial" effect of a soft site is consistent with previous URBAN1-1 (SSI) investigations [42] in which the vibration filtering and isolating effect of soft soil on structures were improved.

The total absorbed energy of individual structures of URBAN6-6 system under the vertically incident $S$ waves that produce motion along the $X$-axis, now for different 


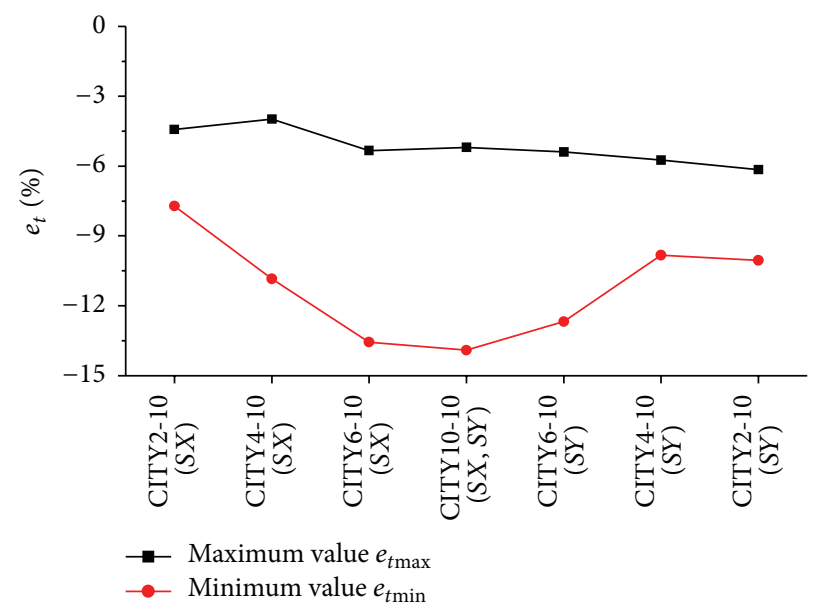

FIGURE 24: Interaction among structures in terms of influence coefficients $e_{t \max }$ and $e_{t \min }$ for structural groups with different arrangements (MCH000, SX or SY).

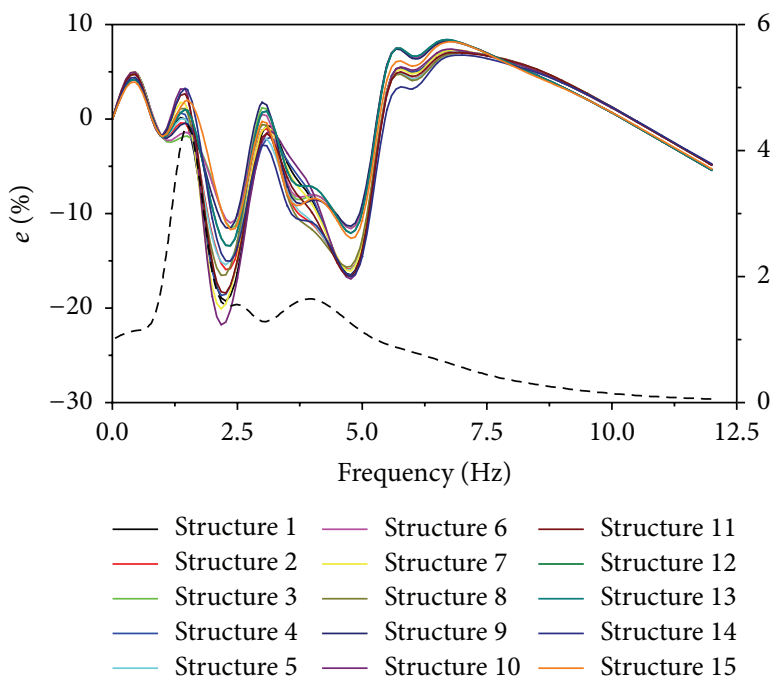

(a) URBAN6-10, $S X, \bar{D}=0.5$
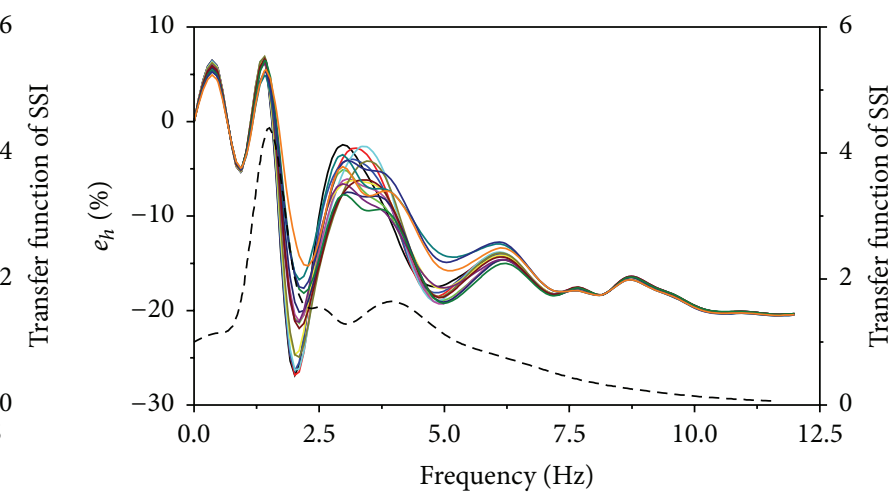

Structure 1
- Structure 2
Structure 3
Structure 4
Structure 5

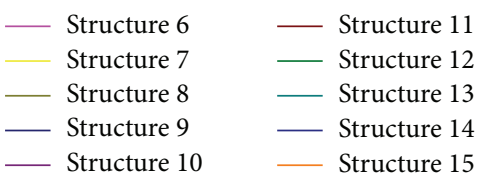

(b) URBAN6-10, $S Y, \bar{D}=0.5$

FIGURE 25: Interaction among structures in terms of influence coefficient $e_{h}$. The solid lines are the influence coefficient $e_{h}$ of URBAN6-10 system. The dashed line is the transfer function $Q$ in the URBAN1-1 (SSI) system.

shear wave velocities in every soil layer $\left(\overline{v_{s}}=n v_{s}, n=\right.$ $0.25,0.5,2)$, is presented in Figure 30 . The total absorbed energy of individual structures when $\overline{v_{s}}=v_{s}=361 \mathrm{~m} / \mathrm{s}$ is plotted in Figure 13. The total absorbed energies of every individual structure on a hard or soft site are all less than the response of the corresponding SSI situation, whereas the energy dissipation of structures on a soft site is less than that of structures on a hard site.

The influence coefficient $\beta$ of individual structures of the URBAN6-6 $(\bar{D}=0.5)$ system under vertically incident $S$ waves MCH000 that produce motion along the $X$-axis for $\overline{v_{s}}=0.5 v_{s}$ is plotted in Figure 31. For an urban area built on a very soft site, the buildings located in the urban fringe still absorb less earthquake energy than the downtown buildings. For individual structures, even the amplitude of $\beta$ is unequal, and the general trend is similar.
The change in the subsoil shear wave velocity also alters the modified trend of the SSSI effect on the ground seismic motions. The PGA distribution in the first quadrant of URBAN6-6 $\left(\overline{v_{s}}=2 v_{s}\right)$ is plotted in Figure 32. Rather than the phenomena gain observed previously, for an urban area built on a hard site, the PGAs at the building locations are larger than the PGAs at locations between the structures. Nonetheless, the PGAs at the building locations are still slightly less than the PGAs in the free field. Hence, we deduce that the subsoil shear wave velocity can greatly influence the seismic response of an SSSI system, which not only affects the SSSI effect intensities and the effective distance of a structural group but also completely changes the SSSI effect trend.

The soil shear wave velocity also influences the effective distance of a structural group. On a soft site, the effective distance of a structural group is large. As the subsoil 


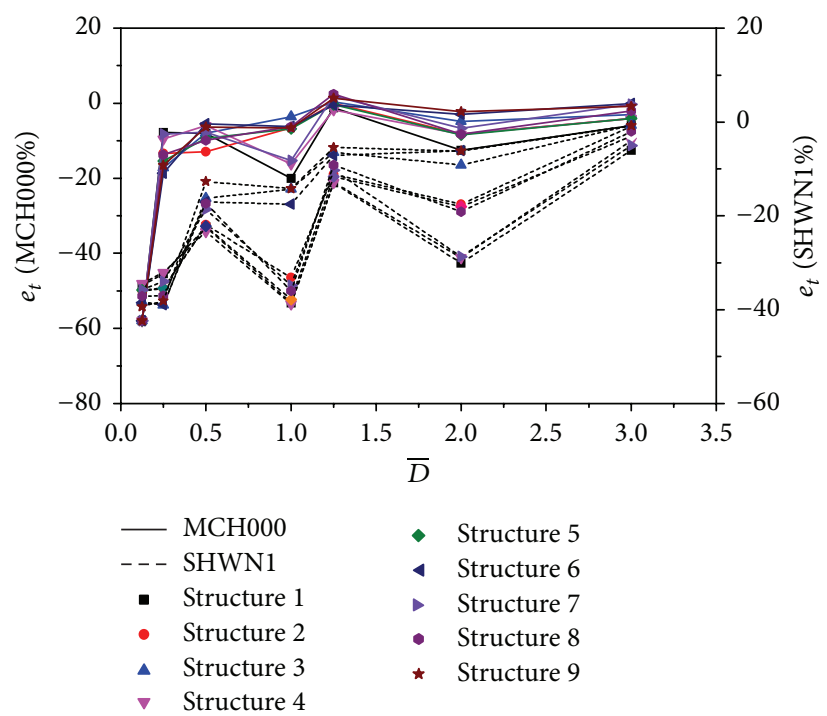

FIGURE 26: Interaction among structures in terms of influence coefficient $e$ for different distances between structures (URBAN6-6, MCH000 or SHWN1, SX).

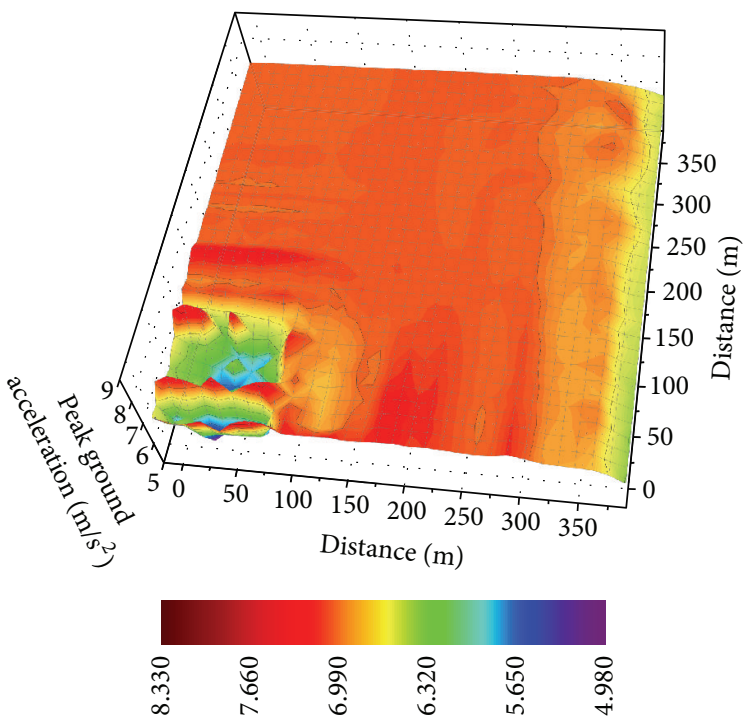

Figure 27: Peak ground acceleration distribution of URBAN6-6 (1/4 FE model, $\bar{D}=0.5$, El Centro, $S X)$.

becomes harder, the effective distance of a structural group decreases. Figure 33 shows the PGA contour of URBAN6-6 $\left(\overline{v_{s}}=2 v_{s}\right)$, of which the urban nondimensional width is 6.0, the nondimensional effective width of structural group parallel to the excitation is 8.0 , and the nondimensional effective width of the structural group perpendicular to the excitation is 7.0. Compared with the urban influence distance gain from Figure 22 (URBAN6-6, $\overline{v_{s}}=v_{s}$ ), the increased subsoil shear wave velocity confines the effective distance of a structural group to a relatively limited area.

\section{Conclusion}

A three-dimensional numerical procedure for the dynamic analysis of a group of pile-high-rise frame structures resting on soil layers was used in this work to address the problem of structure-soil-structure interaction (SSSI). The equivalent linearization method was used to consider the nonlinear phase of subsoil. The results in our paper match the responses observed in the Mexico City earthquake and the 1976 earthquake in Friuli, Italy. The following conclusions can be made with respect to the SSSI effect.

(i) The structure-soil-structure interaction slightly reduces the fundamental frequency of the SSSI system.

(ii) The structure-soil-structure interaction mitigates the structural seismic response, and the absolute value of the influence coefficient $e$ can reach $35 \%$ in the most distinct case. Qualitatively, buildings in the urban 

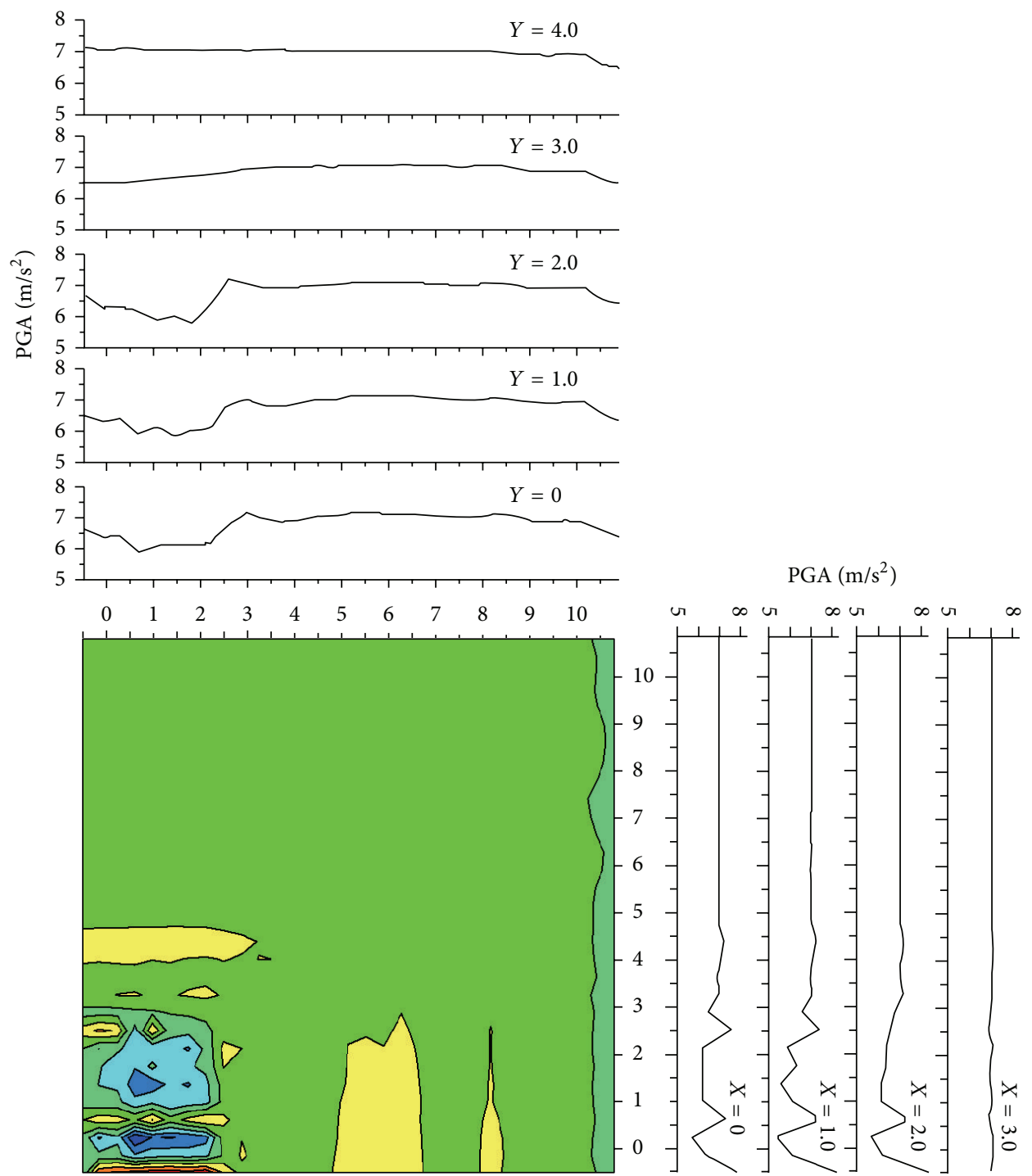

Figure 28: Peak ground acceleration distribution of URBAN6-6 with respect to nondimensional spatial coordinates $(1 / 4 \mathrm{FE}$ model, $\bar{D}=0.5$, El Centro, $S X$. Structure's location is $(0,0),(0,1),(0,2),(1,0),(1,1),(1,2),(2,0),(2,1)$, and $(2,2)$. The urban nondimensional width is 6.0 ; the nondimensional effective width of a structural group parallel to the excitation is 12.0 , and the nondimensional effective width of a structural group perpendicular to the excitation is 9.0).

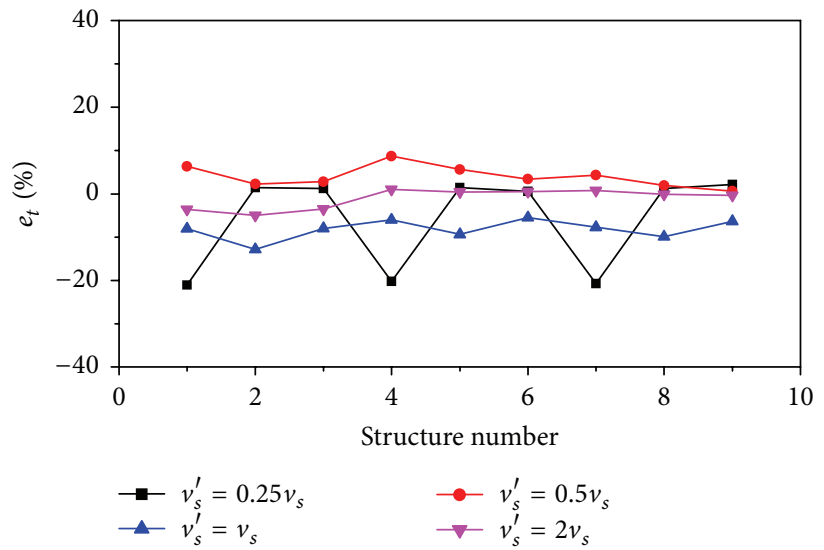

FIGURE 29: Interaction among structures in terms of influence coefficient $e$ with respect to the subsoil shear wave velocity. 

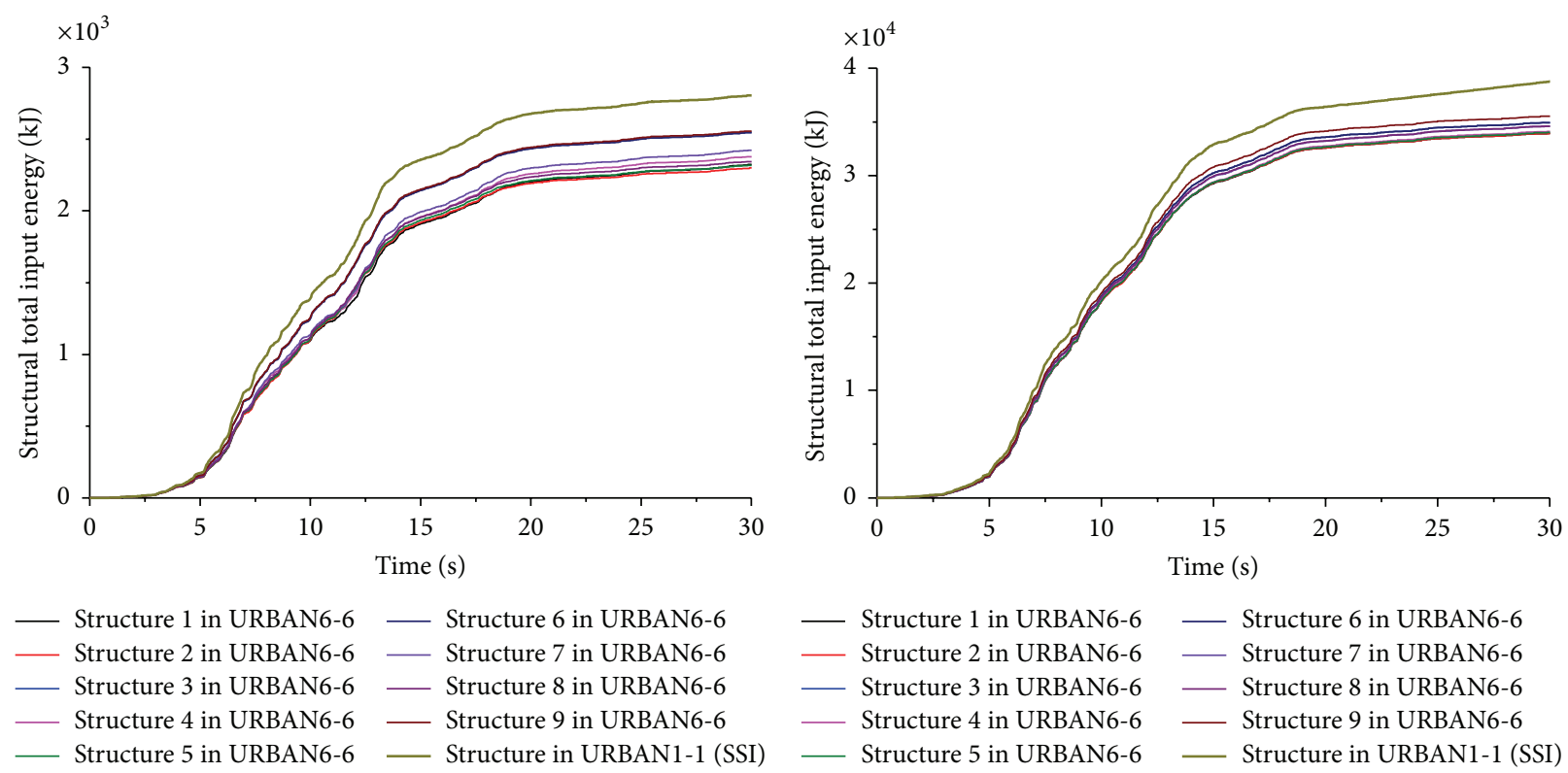

(a) $\overline{v_{s}}=0.25 v_{s}=90 \mathrm{~m} / \mathrm{s}$
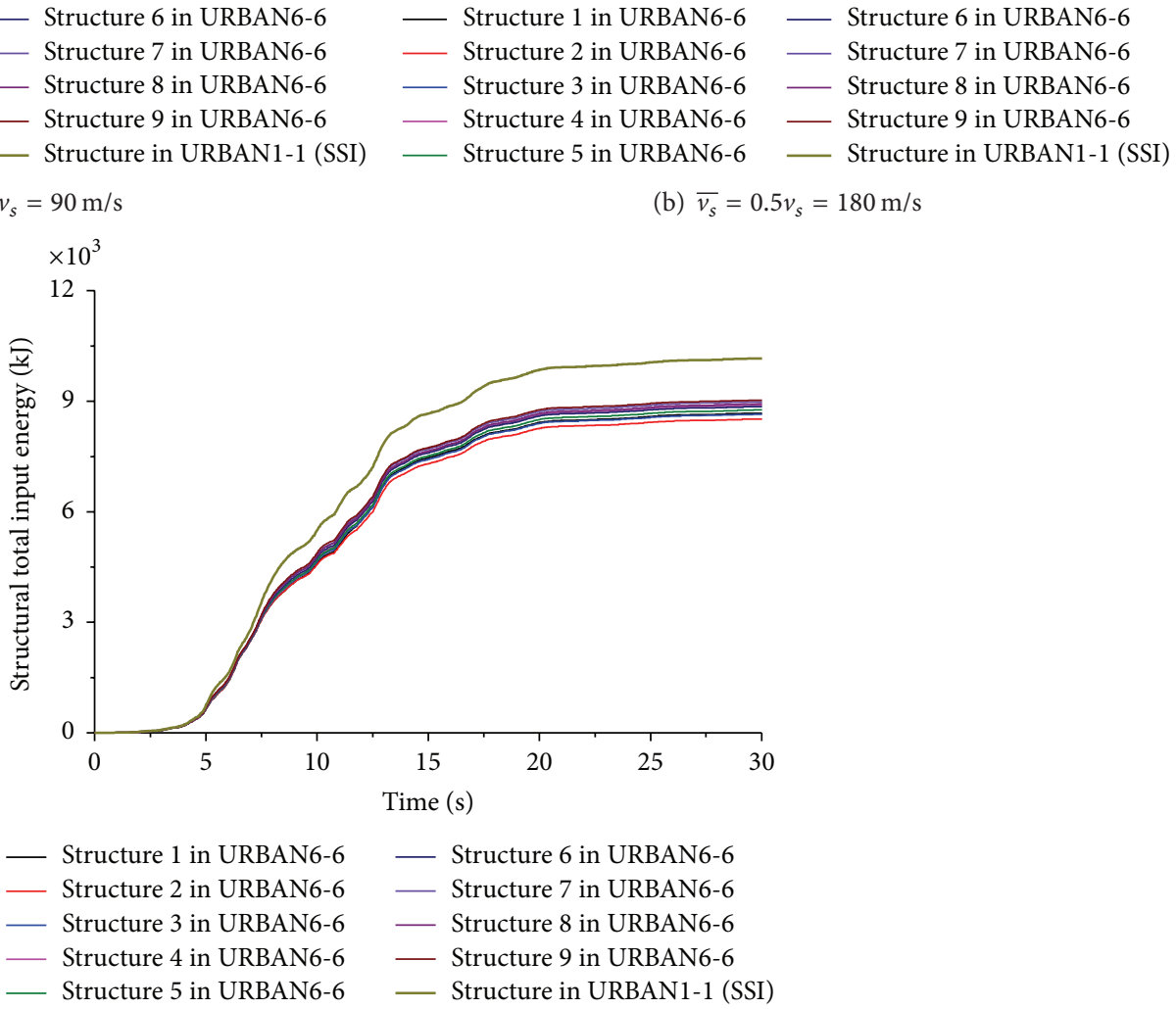

(c) $\overline{v_{s}}=2 v_{s}=722 \mathrm{~m} / \mathrm{s}$

FiguRE 30: Structural total absorbed energy (URBAN6-6, $\bar{D}=0.5, \overline{v_{s}}=n v_{s}, n=0.25,0.5,2$, MCH000, $S X$ ).

fringe are subjected to stronger shaking than downtown buildings.

(iii) The seismic response on the ground is variable due to the SSSI, and the overall trend of the SSSI effect reduces the ground motions inside an urban area. For an urban area built on a soft site, the PGA at the building locations decreases; at the locations between the structures, the PGA is relatively higher, even higher than the PGA in a free field in certain locations. Furthermore, the ground motions at building locations change with alternating peaks. (iv) The effective width of the structural group on ground motions is associated with the urban width. The effective width of a structural group in the direction parallel to the input excitation is larger than that in the direction perpendicular to the input excitation. For the standard site case in this paper, the effective width of a structural group along the shaking is approximately 2.0 times the urban width, and the effective width of a structural group in the direction perpendicular to the shaking is approximately 1.5 times the urban width. 


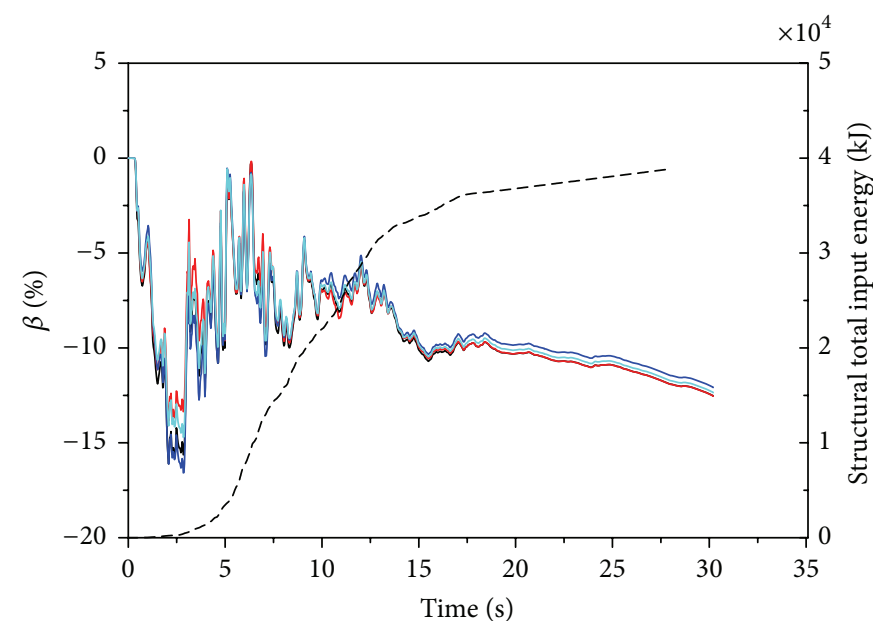

Structure 1 in URBAN6-6
- Structure 2 in URBAN6-6
- Structure 4 in URBAN6-6

(a) $\beta$ of structures number 1 , number 2 , number 4 , and number 5

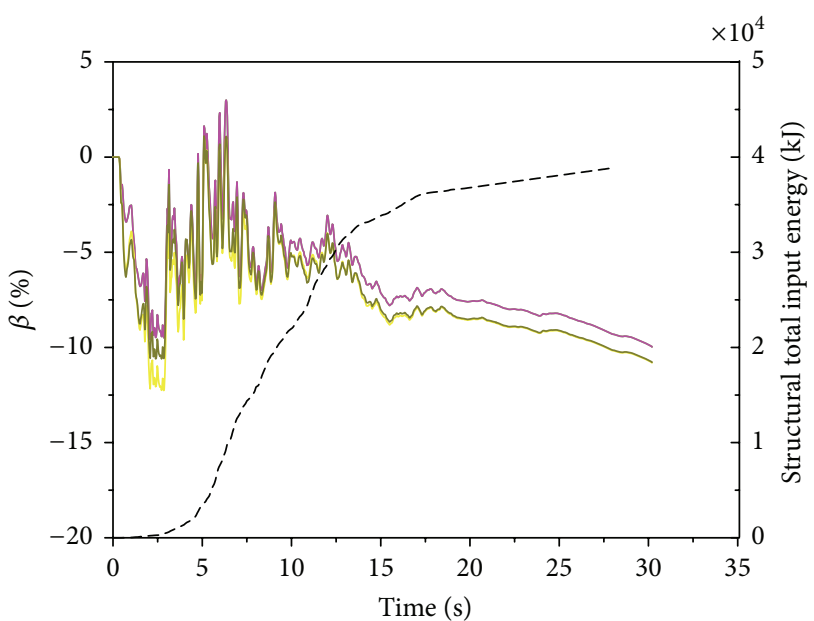

Structure 3 in URBAN6-6 - Structure 8 in URBAN6-6 Structure 6 in URBAN6-6 --- Structure in URBAN1-1 (SSI) Structure 7 in URBAN6-6

(b) $\beta$ of structures number 3 , number 6 , number 7 , and number 8

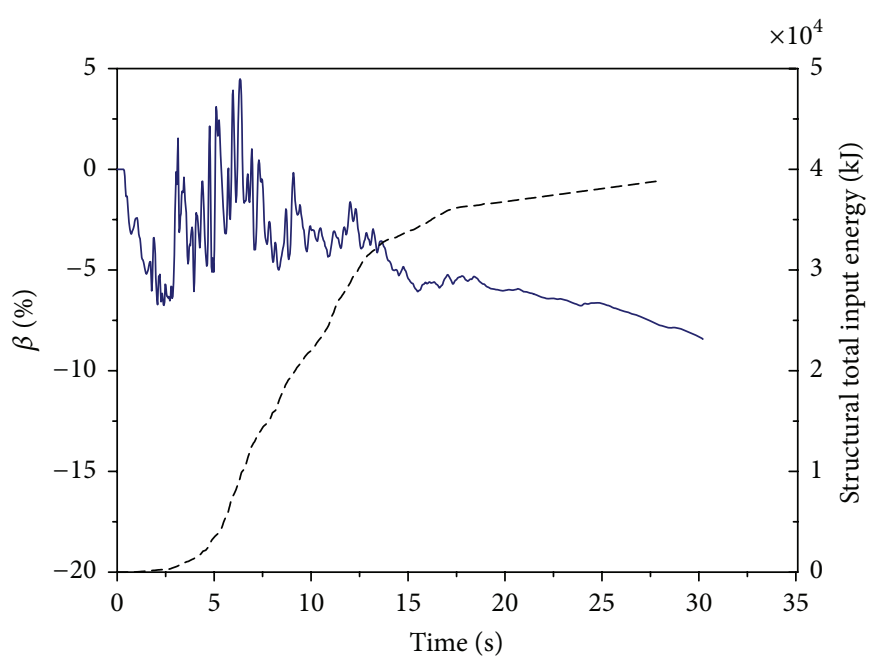

- Structure 9 in URBAN6-6
--- Structure in URBAN1-1 (SSI)

(c) $\beta$ of structure number 9

FIGURE 31: Interaction between structures in terms of influence coefficient $\beta$ (URBAN6-6, $\bar{D}=0.5, \overline{v_{s}}=0.5 v_{s}$, MCH000, SX). The solid lines are the influence coefficient $\beta$ of structures in URBAN6-6. The dashed line is the structural total absorbed energy in the URBAN1-1 (SSI) case.

(v) Less distance between structures reduces ground motions inside an urban area, both at the building locations and at the locations between structures. That is, the "beneficial" effect of the SSSI is enhanced. As the distance between structures decreases, the nonuniformity of ground motions decreases. However, the effective widths of a structural group that is parallel and perpendicular to the shaking are still 2.0 times and 1.5 times the urban width, respectively.

(vi) Soil properties greatly influence the system seismic responses; they not only affect the SSSI effect intensities and effective distances but also completely alter the effect trends. For an urban area built on a hard site, the PGAs at the building locations are larger than the PGAs at locations between buildings. As the shear wave velocity decreases, both the decrease in the degree of PGA and the range of structural responses within the same urban area are enhanced. Additionally, the effective distance of a structural group increases. Furthermore, the "regular" (periodic) damage distribution is noticeable on a soft site.

These results indicate that the soil properties and the distance between structures have a great influence on the seismic performance of an SSSI system. However, the conclusions got 

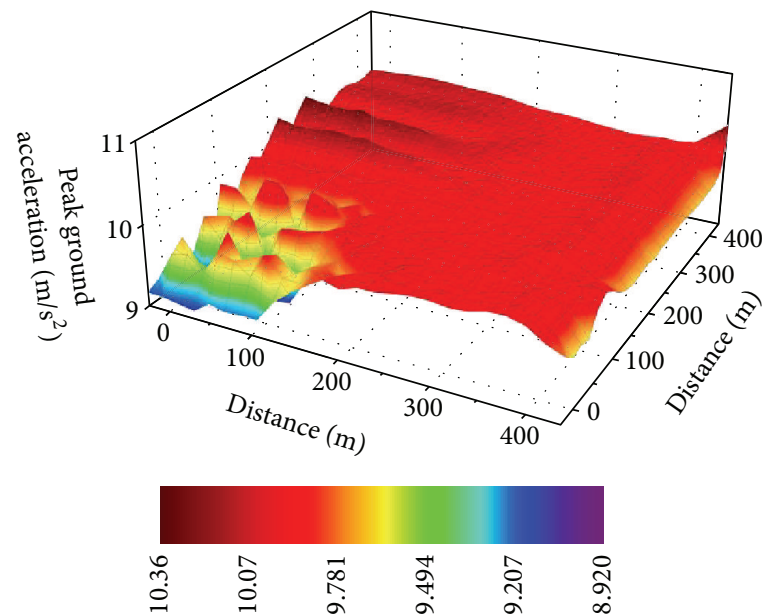

FigURE 32: Peak ground acceleration distribution of URBAN6-6 (1/4 FE model, $\bar{D}=0.5, \overline{v_{s}}=2 v_{s}$, El Centro, $\left.S X\right)$.
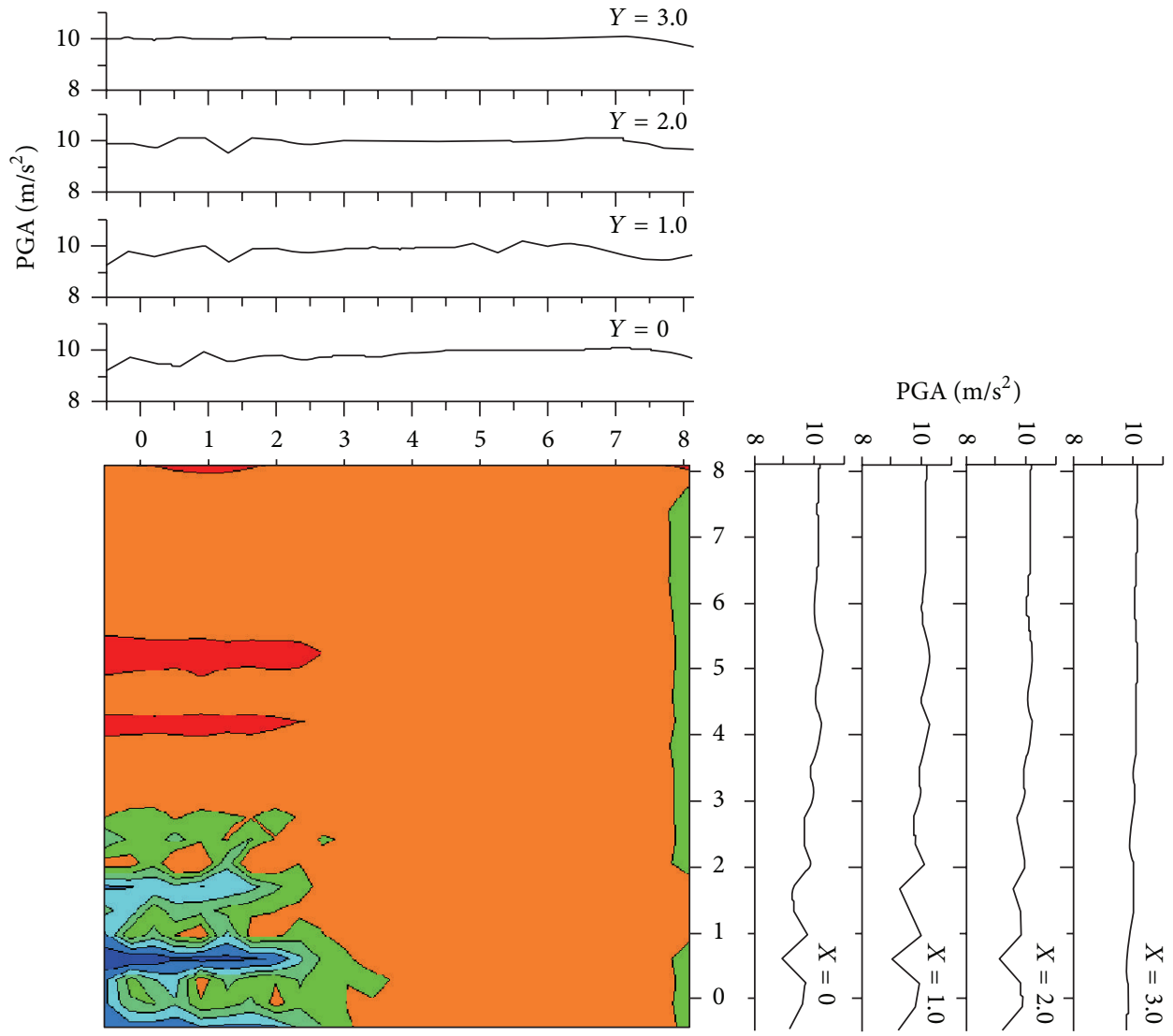

FIgURE 33: Peak ground acceleration distribution of URBAN6-6 with respect to nondimensional spatial coordinates $(1 / 4 \mathrm{FE}$ model, $\bar{D}=1.25$, $\overline{v_{s}}=2 v_{s}$, El Centro, $S X$. The structure location is $(0,0),(0,1),(0,2),(1,0),(1,1),(1,2),(2,0),(2,1)$, and $\left.(2,2)\right)$. The urban nondimensional width is 6.0 , the nondimensional effective width of a structural group parallel to the excitation is 8.0 , and the nondimensional effective width of a structural group perpendicular to the excitation is 7.0.

in this paper are limited by the assumed problem. Noting the uniformity of the structural groups herein, the SSSI effect on a realistic city may be more complex. In the future, it will be necessary to (i) focus more attention on the seismic source; (ii) discuss modifications of the shaking duration, structure damage, ground motion characteristics, and related factors; (iii) include material losses of the structures and underlying soil; (iv) investigate more complex urban arrangements, 
such as including the underground structures and complex grounding structures; and (v) conduct seismic fragility estimation of SSI systems. Overall, SSSI phenomena and their influence on structural seismic risk require additional study for all aspects of the problem.

\section{Conflict of Interests}

The authors declare that there is no conflict of interests regarding the publication of this paper.

\section{Acknowledgments}

This work is supported by the National Science \& Technology Pillar Program of China (Grant no. 2015BAK17B04) and the State Key Laboratory Theory Foundation of the Ministry of Science and Technology of China (Grant no. SLDRCE14-A02). This support is gratefully acknowledged.

\section{References}

[1] T. Iwata, T. Kagawa, A. Petukhin, and Y. Ohnishi, "Basin and crustal velocity structure models for the simulation of strong ground motions in the Kinki area, Japan," Journal of Seismology, vol. 12, no. 2, pp. 223-234, 2008.

[2] B. Savage, Regional Seismic wavefield propagation [Ph.D. thesis], California Institute of Technology, Pasadena, Calif, USA, 2004.

[3] N. Maeda, Y. Nakajima, Matsuda, and N. I. Abeki, "Evaluation of seismic amplification characteristics at a university campus with complicated relief of basement," in Proceedings of the Workshop on Languages and Compilers for Parallel Computing (LCPC '06), Paris, France, November 2006.

[4] A. Wirgin and P.-Y. Bard, "Effects of buildings on the duration and amplitude of ground motion in Mexico City," Bulletin of the Seismological Society of America, vol. 86, no. 3, pp. 914-920, 1996.

[5] P. Gueguen, Seismic interaction between soil and buildings: from soil-structure interaction to site-city interaction [Ph.D. thesis], University of Grenoble, Grenoble, France, 2000.

[6] P. Rys and A. Jc, "Fundamental dynamic behavior of foundations on sand," in ASCE Geotechnical Special Publications, no. 107, pp. 10-19, 2000.

[7] E. Kausel, "Early history of soil-structure interaction," Soil Dynamics and Earthquake Engineering, vol. 30, no. 9, pp. 822832, 2010.

[8] E. Çelebi, F. Göktepe, and N. Karahan, "Non-linear finite element analysis for prediction of seismic response of buildings considering soil-structure interaction," Natural Hazards and Earth System Sciences, vol. 12, no. 11, pp. 3495-3505, 2012.

[9] A. K. Chopra and J. A. Gutierrez, "Earthquake response analysis of multistorey buildings including foundation interaction," Earthquake Engineering and Structural Dynamics, vol. 3, no. 1, pp. 65-77, 1974.

[10] R. S. Jangid and T. K. Datta, "Evaluation of the methods for response analysis under non-stationary excitation," Shock and Vibration, vol. 6, no. 5, pp. 285-297, 1999.

[11] N. Kodama and K. Komiya, "Model tests and FE-modelling of dynamic soil-structure interaction," Shock and Vibration, vol. 19, no. 5, pp. 1061-1069, 2012.
[12] S. Adhikari and S. Bhattacharya, "Dynamic instability of pilesupported structures in liquefiable soils during earthquakes," Shock and Vibration, vol. 15, no. 6, pp. 665-685, 2008.

[13] A. Boominathan and R. Ayothiraman, "Measurement and analysis of horizontal vibration response of pile foundations," Shock and Vibration, vol. 14, no. 2, pp. 89-106, 2007.

[14] S. Kobielak, T. Krauthammer, and A. Walczak, "Ground shock attenuation on a buried cylindrical structure by a barrier," Shock and Vibration, vol. 14, no. 5, pp. 305-320, 2007.

[15] Y.-M. Fang and J.-P. Pu, "Field tests and simulation of lion-head river bridge," Shock and Vibration, vol. 14, no. 3, pp. 181-228, 2007.

[16] M. Iguchi, "Dynamic interaction of soil-structure with elastic rectangular foundation," in Proceedings of the 5th Japanese Earthquake Engineering Symposium, Tokoyo, Japan, 1978.

[17] J. Bielak, "Modal analysis for building-soil interaction," Journal of the Engineering Mechanics Division, vol. 102, no. 5, pp. 771786, 1976.

[18] S. Jarernprasert, E. Bazan-Zurita, and J. Bielak, "Seismic soilstructure interaction response of inelastic structures," Soil Dynamics and Earthquake Engineering, vol. 47, pp. 132-143, 2013.

[19] R. V. Whitman, “The current status of soil dynamics," Applied Mechanics Reviews, vol. 22, no. 1, pp. 1-8, 1969.

[20] J. E. Luco and L. Contesse, "Dynamic structure-soil-structure interaction," Bulletin of the Seismological Society of America, vol. 63, no. 4, p. 1289, 1973.

[21] H. L. Wong and M. D. Trifunac, "Two-dimensional, antiplane, building-soil-building interaction for two or more buildings and for incident plane SH waves," Bulletin of the Seismological Society of America, vol. 6, no. 65, pp. 1863-1885, 1975.

[22] S. Wang and G. Schmid, "Dynamic structure-soil-structure interaction by FEM and BEM," Computational Mechanics, vol. 9, no. 5, pp. 347-357, 1992.

[23] L. Lehmann and H. Antes, "Dynamic structure-soil-structure interaction applying the symmetric Galerkin boundary element method (SGBEM)," Mechanics Research Communications, vol. 28, no. 3, pp. 297-304, 2001.

[24] C. Tsogka and A. Wirgin, "Simulation of seismic response in an idealized city," Soil Dynamics and Earthquake Engineering, vol. 23, no. 5, pp. 391-402, 2003.

[25] D. Clouteau, O. Ishizawa, and N. Mezher, "Seismic wave propagation in a random city," in Proceedings of the 7th National Conference on Earthquake Engineering, Boston, Mass, USA, 2002.

[26] C. Boutin and P. Roussillon, "Assessment of the urbanization effect on seismic response," Bulletin of the Seismological Society of America, vol. 94, no. 1, pp. 251-268, 2004.

[27] N. Mezher, Numerical modelling and quantification of the sitecity seismic effect [Ph.D. thesis], École Centrale Paris, Paris, France, 2004.

[28] J. L. Chazelas, P. H. G. Guen, P. Y. Bard, and J. F. Semblat, "Modeling of the site-city effect with centrifuge small scale model (instrumental techniques validation)," in Proceedings of the 6th National Conference on Earthquake Enginerring, pp. 245-252, Palaiseau, France, 2003.

[29] P. Guéguen, P.-Y. Bard, and F. J. Chávez-García, "Site-city interaction in Mexico City-like environments: an analytical study," Bulletin of the Seismological Society of America, vol. 92, no. 2, pp. 794-811, 2002. 
[30] D. Clouteau and D. Aubry, "Modifications of the ground motion in dense urban areas," Journal of Computational Acoustics, vol. 9, no. 4, pp. 1659-1675, 2001.

[31] R. Y. S. Pak and J. C. Ashlock, "A fundamental dual-zone continuum theory for dynamic soil-structure interaction," Earthquake Engineering and Structural Dynamics, vol. 40, no. 9, pp. 10111025, 2011.

[32] L. A. Padrón, J. J. Aznárez, and O. Maeso, "Dynamic structuresoil-structure interaction between nearby piled buildings under seismic excitation by BEM-FEM model," Soil Dynamics and Earthquake Engineering, vol. 29, no. 6, pp. 1084-1096, 2009.

[33] S. Naserkhaki, F. N. A. A. Aziz, and H. Pourmohammad, "Earthquake induced pounding between adjacent buildings considering soil-structure interaction," Journal of Earthquake Engineering and Engineering Vibration, vol. 11, no. 3, pp. 343358, 2012.

[34] H. Aldaikh, N. A. Alexander, E. Ibraim, and O. Oddbjornsson, "Two dimensional numerical and experimental models for the study of structure-soil-structure interaction involving three buildings," Computers \& Structures, vol. 150, pp. 79-91, 2015.

[35] K. Kusama and Y. Kitada, "Model test on dynamic cross interaction of adjacent building in nuclear power plants. Overview and outcomes of the project," in Proceedings of the 17th International Conference on Structural Mechanics in Reactor Technology, Prague, Czech Republic, August 2003.

[36] T. Yano, Y. Naito, K. Iwamoto, Y. Kitada, and M. Iguchi, "Model test on dynamic cross interaction of adjacent building in nuclear power plants. Overall evaluation on field test," in Proceedings of the 17th International Conference on Structural Mechanics in Reactor Technology, Prague, Czech Republic, August 2003.

[37] Y. Kitada, T. Hirotani, and M. Iguchi, "Models test on dynamic structure-structure interaction of nuclear power plant buildings," Nuclear Engineering and Design, vol. 192, no. 2-3, pp. 205216, 1999.

[38] J. G. Ha and D.-S. Kim, "Evaluation of seismic behavior of soils under nuclear containment structures via dynamic centrifuge test," Nuclear Engineering and Design, vol. 277, pp. 64-75, 2014.

[39] M. Kham, J.-F. Semblat, P.-Y. Bard, and P. Dangla, "Seismic sitecity interaction: main governing phenomena through simplified numerical models," Bulletin of the Seismological Society of America, vol. 96, no. 5, pp. 1934-1951, 2006.

[40] F. Ostadan, SASSI2000-A System for Analysis of Soil-Structure Interaction, User's Manual, University of California, Berkeley, Calif, USA, 2000.

[41] K. Uenishi, "The town effect: dynamic interaction between a group of structures and waves in the ground," Rock Mechanics and Rock Engineering, vol. 43, no. 6, pp. 811-819, 2010.

[42] X. Lu, Y. Chen, B. Chen, and P. Li, "Shaking table model test on dynamic soil-structure interaction system," Journal of Asian Architecture and Building Engineering, vol. 1, no. 1, pp. 55-64, 2002. 

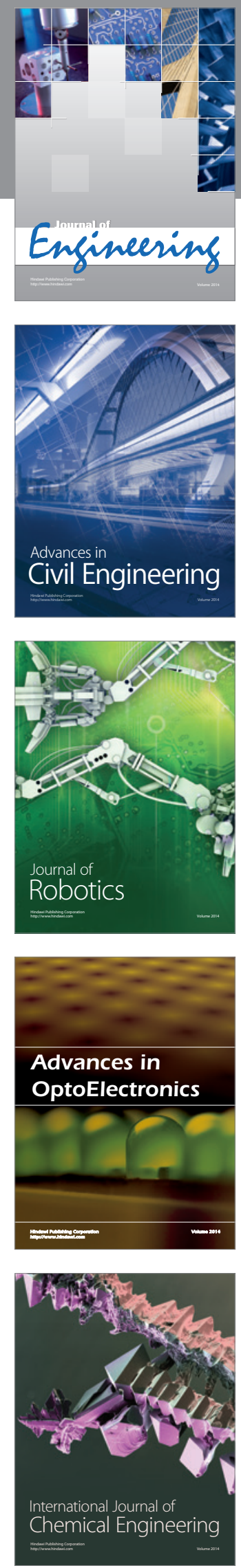

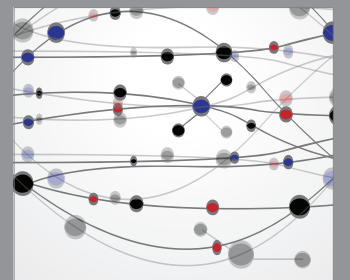

The Scientific World Journal
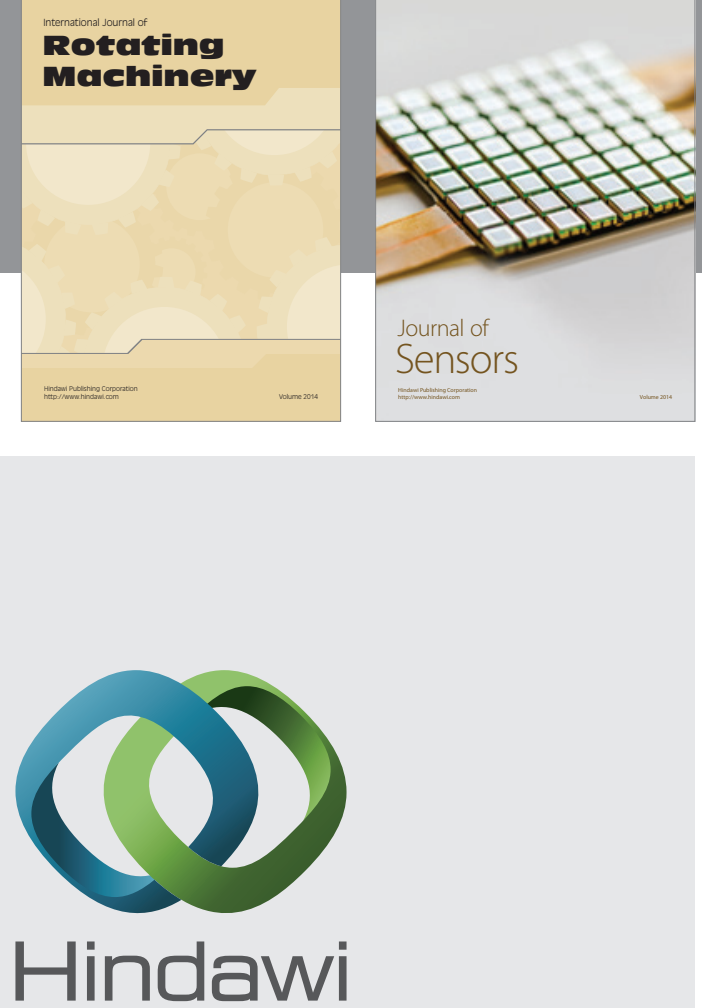

Submit your manuscripts at http://www.hindawi.com
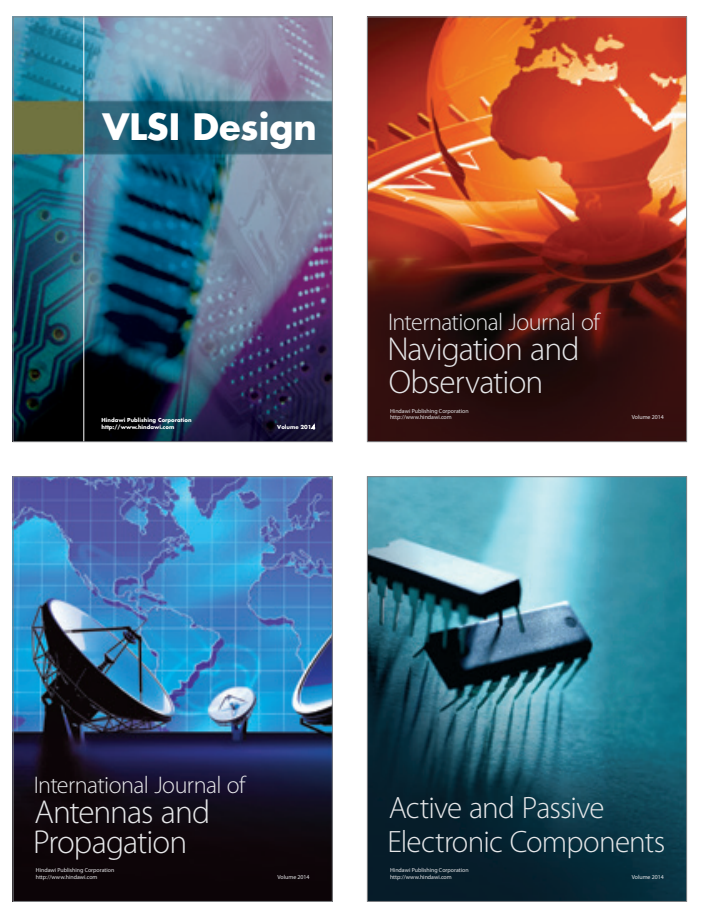
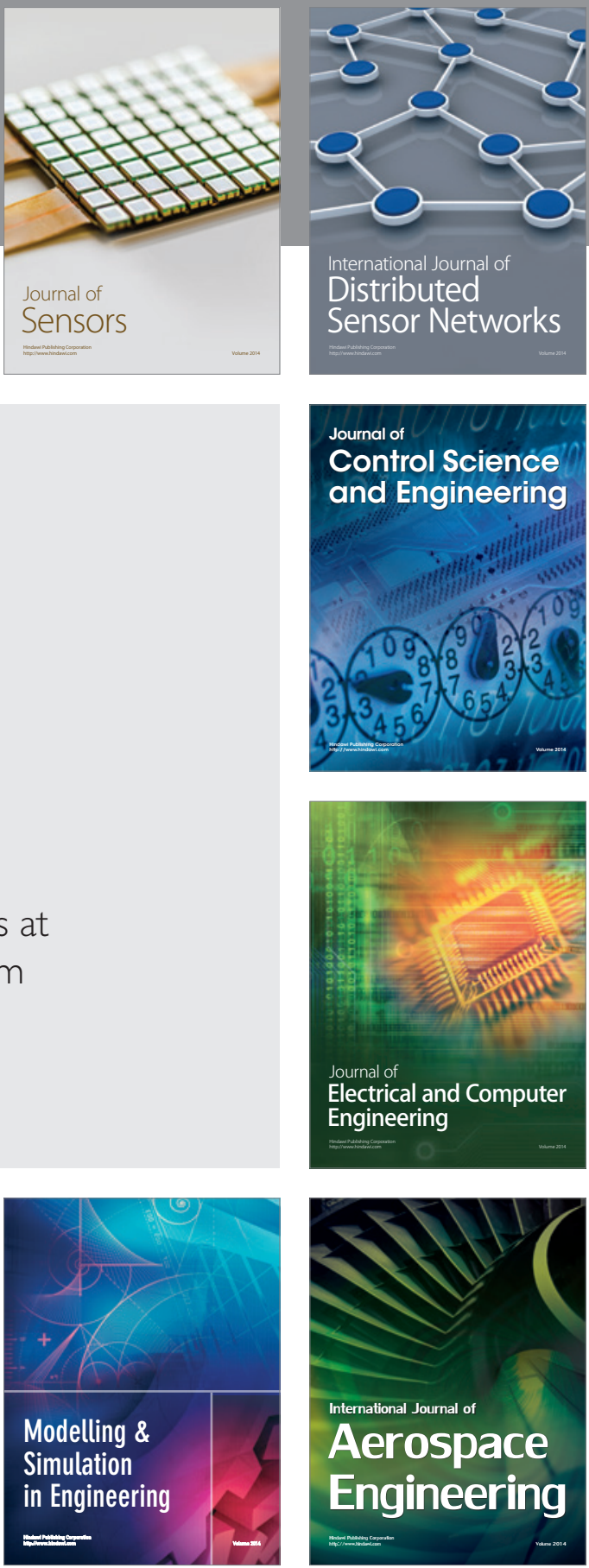

Journal of

Control Science

and Engineering
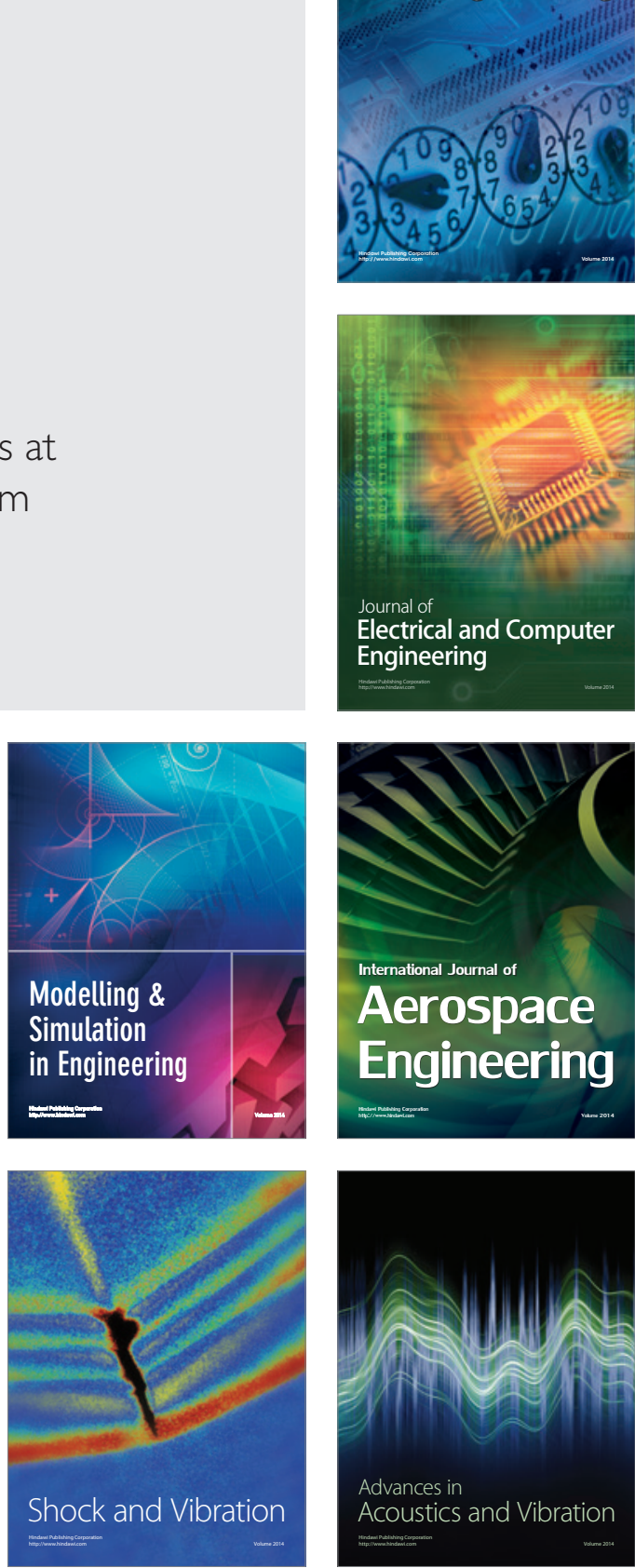